
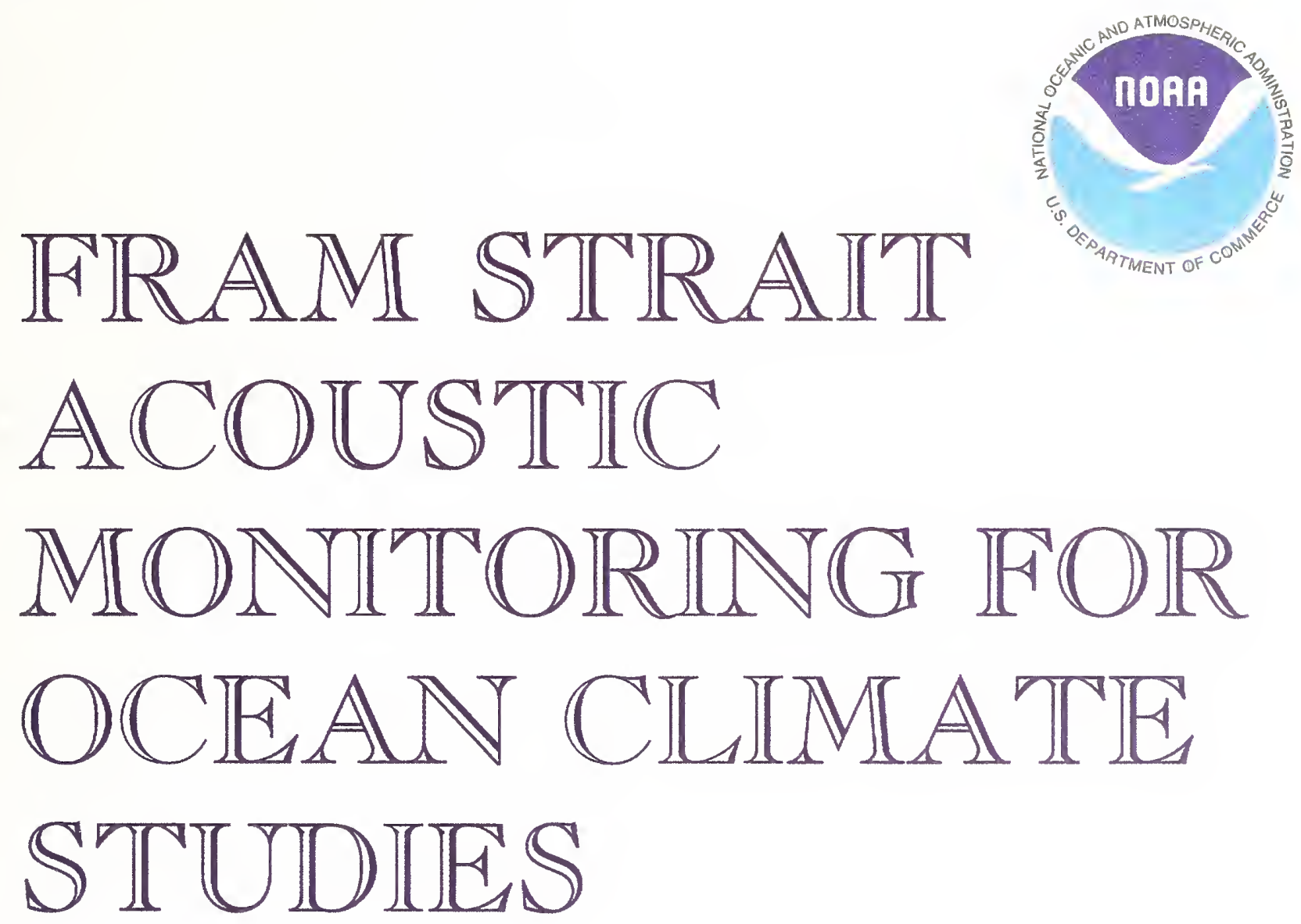

\section{A Workshop Report}

September 25 to 26,1996
Pennsylvania State Uiniversity Libraries

OCT 031997

Documents Collection U.S. Depository Copy
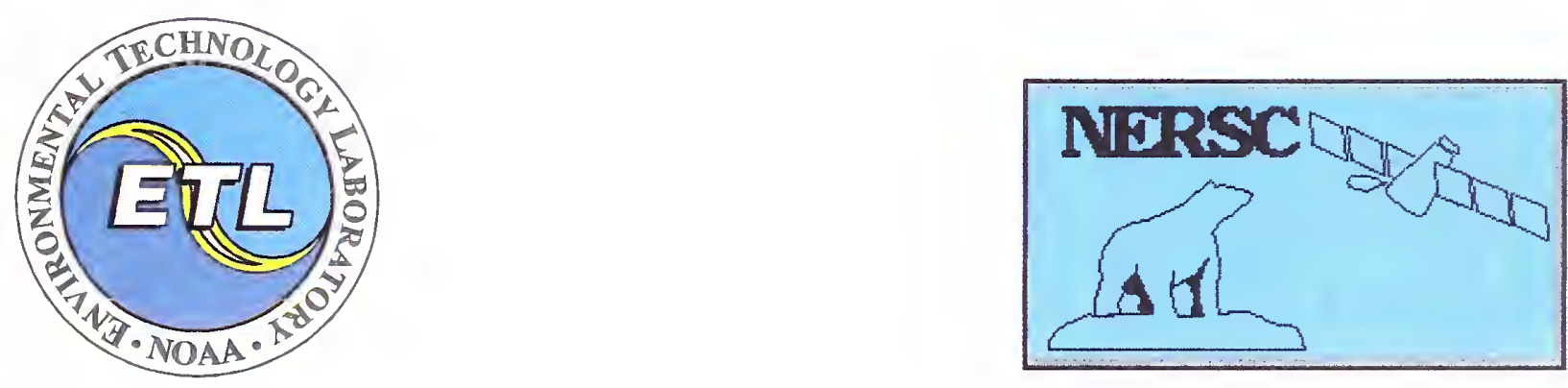

Ola M. Johannessen, ${ }^{1}$ Konstantin A. Naugolnykh, ${ }^{2}$ and Er-Chang Shang. ${ }^{2}$ Editors

'Nansen Environmental and Remote Sensing Center, Bergen, Norway

${ }^{2}$ Cooperative Institute for Research in Environmental Sciences (CIRES). University of Colorado/

NOAA, Environmental Technology Lahoratory, Boulder, Colorado 



\section{Digitized by the Internet Archive in 2013}




\section{NOTICE}

Mention of a commercial company or product does not constitute an endorsement by NOAA/ERL. Use for publicity or advertising purposes of information from this publication or concerning proprietary products or the tests of such products is not authorized. 


\section{CONTENTS}

EXECUTIVE SUMMARY $\ldots \ldots \ldots \ldots \ldots \ldots \ldots \ldots \ldots \ldots \ldots \ldots \ldots \ldots \ldots$

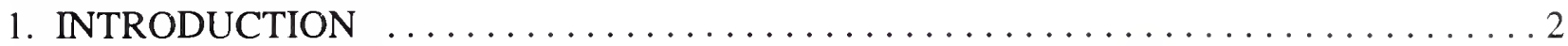

2. OCEANOGRAPHIC MODEL $\ldots \ldots \ldots \ldots \ldots \ldots \ldots \ldots \ldots \ldots \ldots \ldots \ldots \ldots \ldots \ldots \ldots \ldots$

2.1 The Sound Speed Field Structure $\ldots \ldots \ldots \ldots \ldots \ldots \ldots \ldots \ldots \ldots \ldots \ldots \ldots \ldots \ldots \ldots$

2.2 Ocean Temperature-Increasing Model . . . . . . . . . . . . . . . . 8

3. ACOUSTIC PROPAGATION SIMULATION $\ldots \ldots \ldots \ldots \ldots \ldots \ldots \ldots \ldots \ldots \ldots$

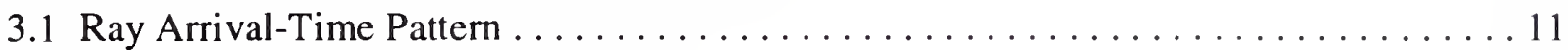

3.2 Sensitivity of Cumulative Summation $\ldots \ldots \ldots \ldots \ldots \ldots \ldots \ldots \ldots \ldots$

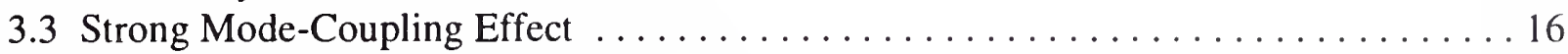

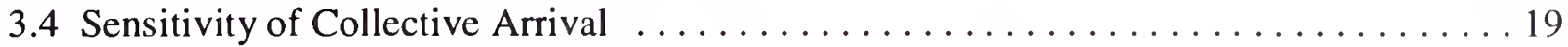

3.5 Current Measurement . . . . . . . . . . . . . . . . . . . . . . . . 19

4. PARAMETRIC ARRAY AS A MODE-SELECTIVE SOURCE . . . . . . . . . . 23

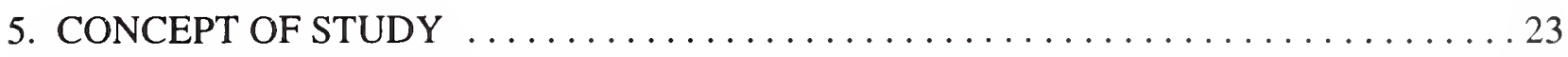

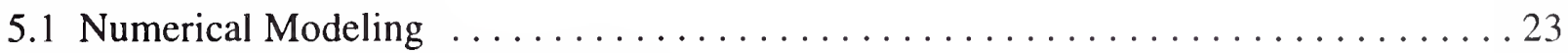

5.1 .1 Physical oceanographic data . . . . . . . . . . . . . . . . . 29

5.1 .2 Forward propagation modeling . . . . . . . . . . . . . . . . 29

5.1 .3 Inverse problem . . . . . . . . . . . . . . . . . . . . . . . . 29

5.1 .4 Observing system simulation experiments . . . . . . . . . . . . . 29

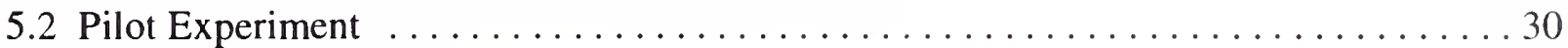

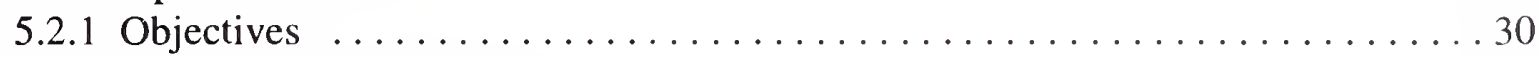

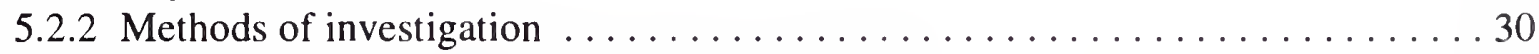

5.2 .3 Expected achievements and the project period $\ldots \ldots \ldots \ldots \ldots \ldots \ldots \ldots \ldots \ldots$

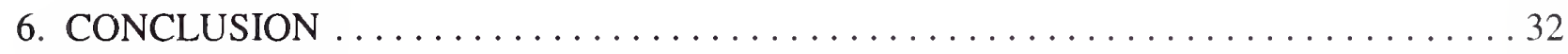

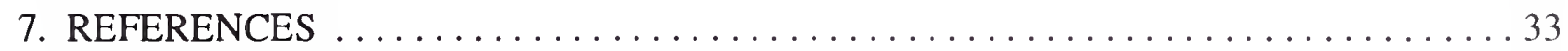

Appendix A: Fram Strait Workshop List of Attendees $\ldots \ldots \ldots \ldots \ldots \ldots \ldots$

Appendix B: Fram Strait Workshop Agenda $\ldots \ldots \ldots \ldots \ldots \ldots \ldots \ldots \ldots \ldots$ 



\section{EXECUTIVE SUMMARY}

The Fram Strait Acoustic Monitoring for Ocean Climate Studies Workshop was held at the NOAA Environmental Technology Laboratory in Boulder, Colorado, on September 25-26, 1996. The workshop was convened to discuss and develop a prioritized scientific plan focused on a systems approach to the oceanographic investigation of the Fram Strait. Major topics discussed during the workshop included the following:

- monitoring of heat and water mass influx through the Fram Strait as part of a general problem of Arctic warming

- acoustic tomography monitoring of the Fram Strait

- monitoring of flux into the Arctic

- planning of a pilot experiment and feasibility test

The following issues and questions emerged from the workshop deliberations:

(1) The Arctic Ocean is a system of high climate sensitivity. An enhanced greenhouse warming in the Arctic relative to lower latitudes by a factor of $2-4$ will have a drastic impact on ice-pack shrinking and the global climate.

(2) The heat flux exchange between the Arctic and the North Atlantic at the Fram Strait plays a significant role in the global climate studies for ATOC-Arctic. Acoustic monitoring of the heat flux at the Fram Strait is proposed, and issues related to the acoustic propagation in this extremely complex environment are investigated.

(3) Different methods of acoustic temperature and current measurements will be considered, including

- arrival-time variation for temperature and along-path current measurement

- parametric array for selective mode excitation to increase the sensitivity of the method

- scintillation technique for across-path current measurement

- horizontal refraction tomography for current and mesoscale structure identification

Acknowledgments. We would like to thank all the participants of the workshop for their active involvement during the meeting. In addition, we appreciate the assistance of Sharon Kirby-Cole and Karen Martin during the workshop and in report preparation. Funding for the workshop was cosponsored by the NOAA Environmental Technology Laboratory (USA) and the Nansen Environmental and Remote Sensing Center (Norway). This project was partially supported NATO Linkage Grant (E.NVIR.L G 960352) 528 (96) LVdC). 


\section{INTRODUCTION}

In a meeting in Rome in December 1995, the Intergovernmental Panel on Climate Change (IPCC) concluded that the observed global warming of $0.4^{\circ}-0.6^{\circ} \mathrm{C}$ in the last century is partly caused by human activity (Hasselmann, 1993; IPCC, 1996a-c). The increasing emission of greenhouse gases into the atmosphere is predicted to cause an average global warming in the next century of approximately $3^{\circ} \mathrm{C}$ (Cubasch et al., 1995; Mitchell et al., 1995) with enhanced effects in the Arctic region. Due to the lack of an integrated monitoring system of oceanographic parameters sensitive to climate change, apart from sea-ice monitoring from satellites (Johannessen et al., 1995a, 1996), there are no adequate observations for estimating the largescale ocean temperature variability, which can be considered as a noise background where the greenhouse gas-induced warming signal must be detected. Today, we have to rely on model estimates, based on poor observational records, for both the global warming signal and the ambient background climate noise.

Climate modeling studies have suggested that the Arctic region will show the strongest atmospheric warming in response to increased greenhouse effect (Manabe et al., 1991; Cattle and Crossley, 1995). This may cause a melting of the sea ice (Semtner, 1987; Johannessen et al., 1995a,b) and a warming of the Atlantic water being advected through the Fram Strait and the St. Anna Trough, causing an increase of the internal temperature of the Arctic Ocean (Macdonald, 1996). Therefore, the Fram Strait, with inflow and outflow from the Arctic Ocean, is a key area to study the integrated effect of global warming both on the Nordic Seas and on the Arctic Ocean itself (Fig. 1).

The Fram Strait is the region where almost all heat and water exchange between the Arctic Ocean and the Atlantic Ocean occurs, apart from the Atlantic inflow through the St. Anna Trough. To a first-order approximation, the Strait acts both as an entry and an exit port for the Arctic Ocean. The general large-scale ocean circulation in this region is dominated by the shallow, southward-flowing, cold, low-salinity East Greenland current (EGC) that exports ice and polar water out of the Arctic Ocean, and the northward-flowing, warm, saline Atlantic water in the West Spitsbergen current (WSC), shown in Fig. 2. Heat inflow through the Fram Strait in proportion to the total is about $80 \%$ (see Table 1).

The water mass exchanges through the Fram Strait are essential boundary conditions for large-scale ocean circulation and global climate models. In recognition of this fact, the observational focus in the Fram Strait region has been on measuring the fluxes of mass and heat through the Strait in order to better understand the difficult-to-observe water mass structure, due to the ice, of the Arctic Ocean (Aagaard and Carmack, 1994). Often, estimates have been made combining current data and hydrographic data obtained at different times and locations. This has resulted in a large spread of the estimated values. Previous estimates of volume transport of the WSC across $79^{\circ} \mathrm{N}$ vary from $1.9 \times 10^{6}$ to $8 \times 10^{6} \mathrm{~m}^{3} \mathrm{~s}^{-1}$ (Simonsen and Haugan, 1996). This large variation in water mass exchange introduces errors in ocean circulation models. 


\section{Monitoring at the Top of the World}

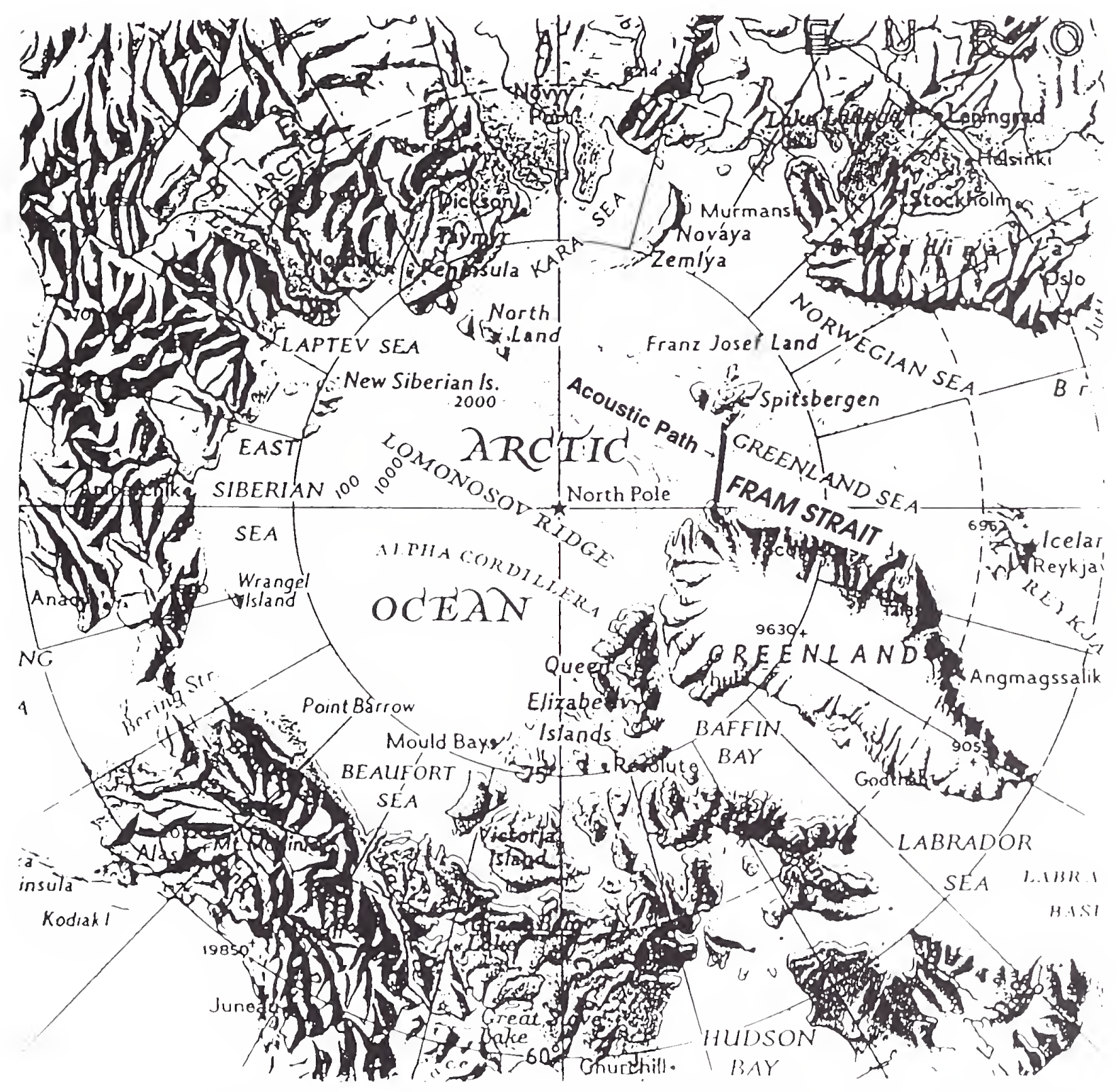

Figure 1. The Fram Strait is a key area to study the integrated effect of global warming. 


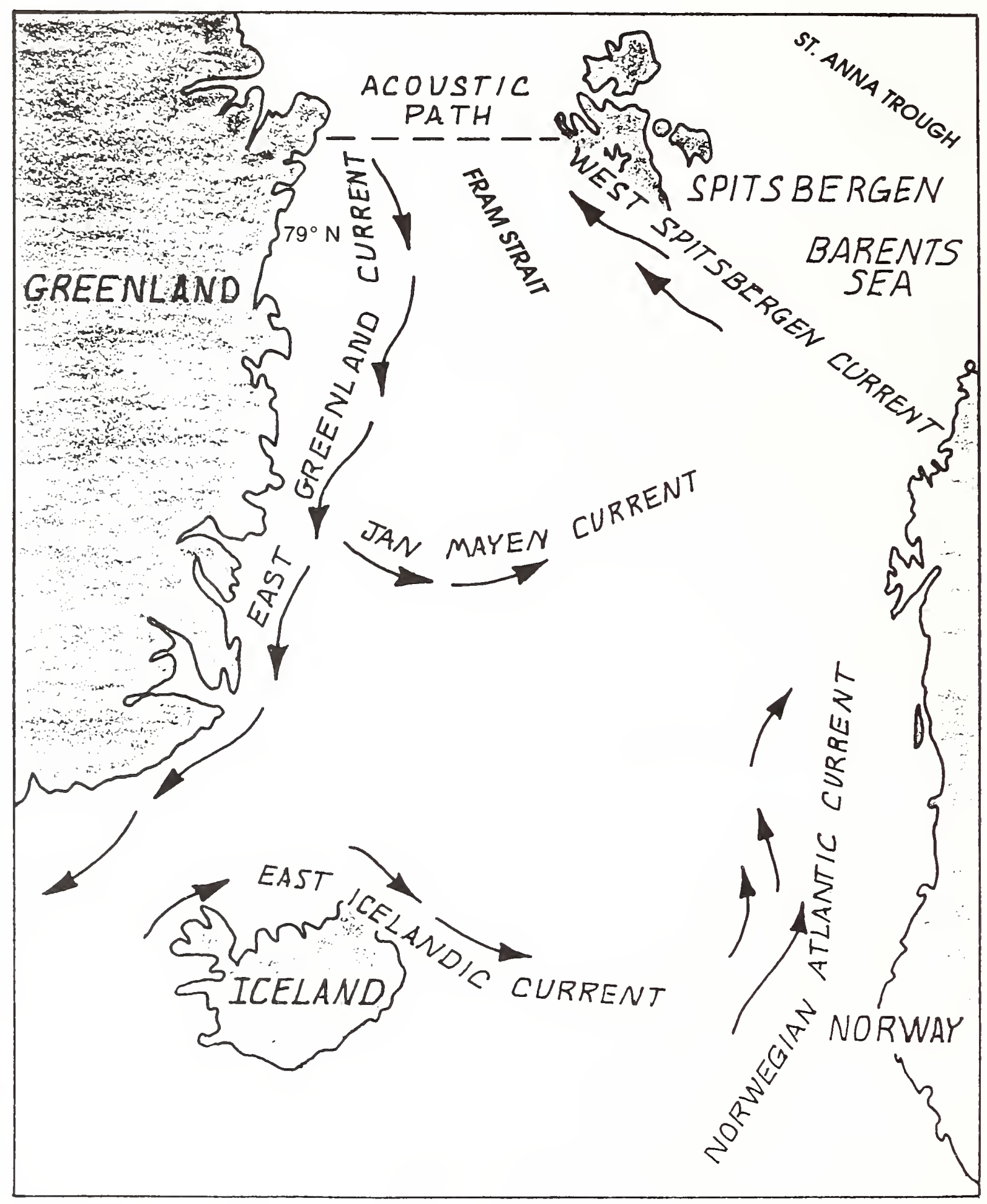

Figure 2. Ocean current structure. 
TABLE 1. Heat Flux Exchange Rate through the Fram Strait ${ }^{\dagger}$

\begin{tabular}{lccc}
\hline & $\begin{array}{c}\text { Volume Transport } \\
\left(\mathrm{S}_{\mathrm{v}}\right)\end{array}$ & $\begin{array}{c}\text { Heat Transport } \\
\left(10^{9} \mathrm{kcal} \mathrm{S}\right)\end{array}$ & $\begin{array}{c}\text { Mean Temperature } \\
\left({ }^{\circ} \mathrm{C}\right)\end{array}$ \\
\hline $\begin{array}{l}\text { East Greenland current } \\
\quad \text { Polar water }\end{array}$ & -1.8 & 2.0 & -1.2 \\
$\quad$ Atlantic water & -5.3 & -3.2 & - \\
$\quad$ Ice & -0.1 & 8.0 & 2.2 \\
West Spitsbergen current & 7.1 & 16.3 & 1.8 \\
Total inflow & 9.4 & - & - \\
Total outflow & -9.4 & -1 & - \\
Total advective heat & - & 29.7 & - \\
Total advective heat loss & - & -3.9 & \\
Net exchange & 0.0 & 25.8 & \\
Heat inflow of the Fram Strait in proportion to the total: $80 \%$ & \\
\hline \\
\hline
\end{tabular}

The main problem in the investigation of straits in general is the lack of synoptic and high-temporal resolution hydrographic and current measurements to estimate the volume and heat flux through straits. The objective of the Fram Strait monitoring project is to measure synoptic temperature and inflow and outflow in order to improve estimates of volume and heat flux through the Fram Strait. Acoustic techniques can play an important role in this monitoring because of the spatial averaging that is inherent in the methods.

Both passive and active methods in underwater acoustics have become important in detection, exploration, and communication systems for use in oceanographic investigations and in the oil industry. A promising method, and probably the only one to measure gyre-scale average ocean temperature, is to use acoustic monitoring based on the concept of Acoustic Thermometry of Ocean Climate (ATOC; Munk and Forbes, 1989). This concept is an extension of acoustic tomography, also pioneered by Walter Munk (Munk, 1994; Munk et al., 1995). Acoustic tomography has been successfully used to study, for example, ocean mesoscale (Cornuelle et al., 1985), a small-scale ocean structure (Cornuelle and Howe, 1987), and the deep water convection in the Greenland Sea (Worcester et al., 1993), and in other experiments (Cornuelle et al., 1985; Cornuelle and Howe, 1987). The acoustic thermometry concept was tested successfully in the Heard Island Feasibility Test, conducted in early 1991 (Munk et al., 1994; Heard Island Papers, 1994). During a pilot Transarctic Acoustic Propagation (TAP) experiment conducted by Mikhalevsky et al. $(1994,1995)$ in the spring of 1994, long-range propagation $(2700 \mathrm{~km})$ through the Arctic Basin was performed. The TAP experiment demonstrated that transmission across the Arctic Basin is possible at a source frequency of $20 \mathrm{~Hz}$. Some data about the ice cover effect on the sound propagation were obtained by Jin et al. (1993, 1994). 
A series of experiments of steadily increasing ranges from 25 to $1275 \mathrm{~km}$ have explored the feasibility of using reciprocal acoustic transmission to measure large-scale ocean current. In the 1987 Reciprocal Tomography Experiment, located in the central North Pacific Ocean, the eight tidal current components, amplitudes, and phases calculated by acoustic methods were in excellent agreement with barotropic tidal current computed from a current meter mooring (Luther et al., 1991; Munk et al., 1995); further excellent agreement has been found with the Ocean Topography Experiment (TOPEX) altimetry data (Dushaw et al., 1997). A first attempt to study the possibility of using two-dimensional acoustic propagation to monitor a stratified shear flow was made by Farmer (Farmer and Di Iorio, 1996). The experiment was designed to study the fine structure of the turbulent current in a 3-km-long, 1-km-wicie, 30-m-deep channel using high-frequency sound $(67 \mathrm{kHz})$. Based on this investigation, they concluded that twodimensional acoustic arrays can provide an effective tool for studying the stratified shear flows in coastal regions, especially for determining the component of the flow perpendicular to the acoustic path. The philosophy of using acoustic arrays (sources and receivers) to measure the current structure can be transferred to similar concepts for a much larger strait, such as the Fram Strait, using frequencies below $200-500 \mathrm{~Hz}$ and larger array configurations (see Fig. 1). Effects of ice cover on the acoustic signal propagation (Jin et al., 1993, 1994) have to be taken into account.

Based on the above scientific rationale, the Scientific Committee on Oceanic Research Working Group (SCOR WG) 96 made the following recommendations:

"The SCOR WG 96 recognizes the particular sensitivity of high-latitude regions to global warming and identifies the desirability of an early implementation of an Arctic acoustic monitoring program."

A novel concept for an Arctic Ocean Climate Monitoring System is outlined in Fig. 3 (Mikhalevsky et al., 1994, 1995). It represents an innovative, unique system combining acoustic remote sensing of the ocean and remote sensing of ice from space (Johannessen et al., 1995a), including modeling and data assimilation (Evensen, 1994a,b). However, in this project the focus is on the feasibility of using acoustic techniques for monitoring volume and heat flux through the Fram Strait, as indicated by the shading of the Strait component in Fig. 3.

Summing up, we conclude the following:

(1) The Arctic Ocean is a system of high climate sensitivity. An enhanced greenhouse warming in the Arctic relative to lower latitudes by a factor of 2-4 will have a drastic impact on ice-pack shrinking and the global climate.

(2) The heat flux exchange between the Arctic and the North Atlantic at the Fram Strait plays a significant role in the global climate studies for ATOC-Arctic. Acoustic monitoring of the heat flux at the Fram Strait is proposed, and issues related to the acoustic propagation in this extremely complex environment are investigated. 
(3) Different methods of acoustic temperature and current measurements will be considered, including

- arrival-time variation for temperature and along-path current measurement

- parametric array for selective mode excitation to increase the sensitivity of the method

- scintillation technique for across-path current measurement

- horizontal refraction tomography for current and mesoscale structure identification

\section{Arctic Ocean Climate Monitoring System}

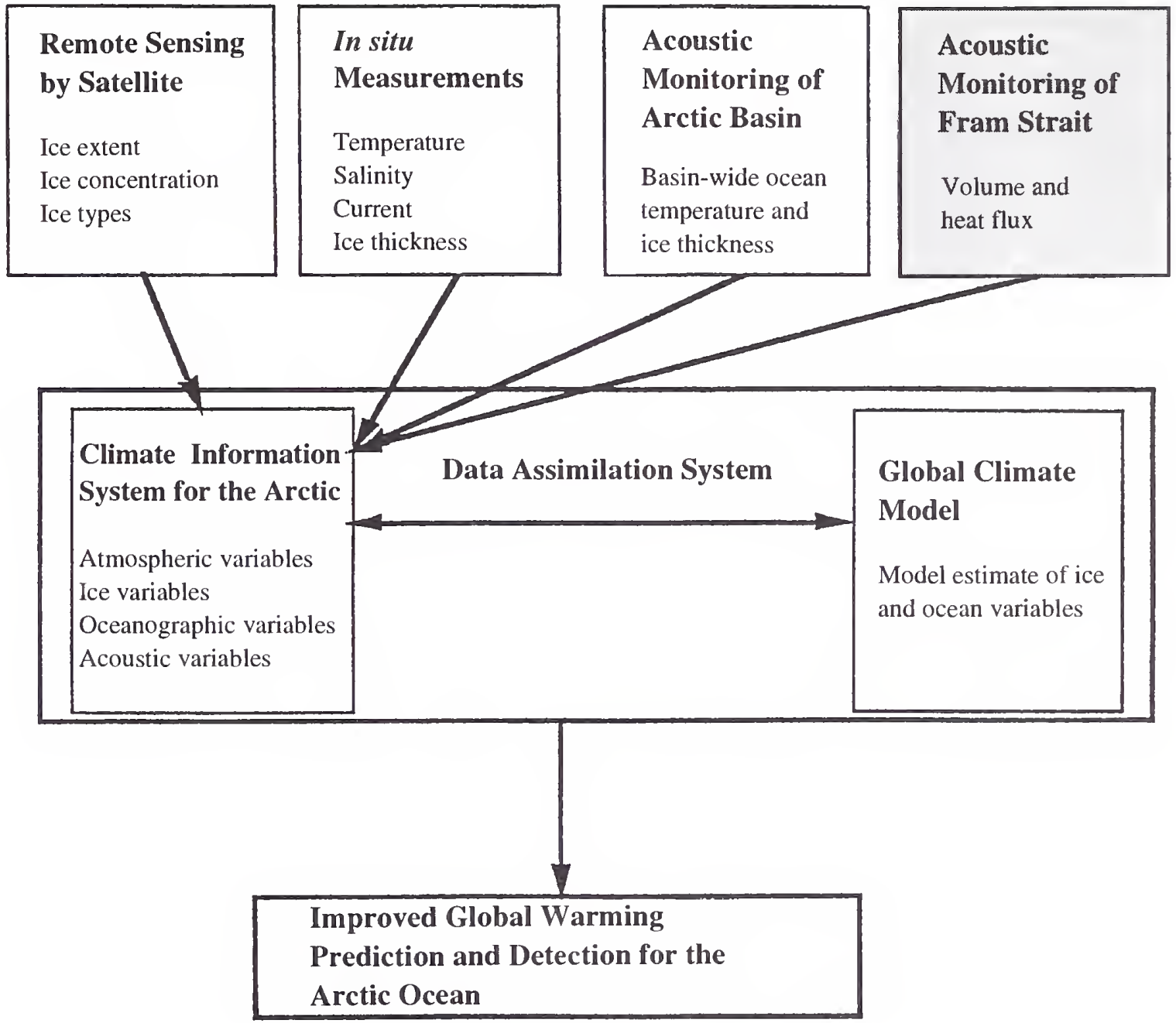

FiguRE 3. Combined remote-sensing system for Arctic climate monitoring. 


\section{OCEANOGRAPHIC MODEL}

\subsection{The Sound Speed Field Structure}

To model the sound propagation in the Fram Strait, a region along $79^{\circ} \mathrm{N}$ latitude could be chosen where an oceanographic cross section was performed by the R/V Polarstern expedition in March 1993. A map of the region with bathymetry and sound speed channel depth distributions, as well as the suggested positions of the acoustic transmitter (T) and receiver (R), is shown in Fig. 4. Figure 5 shows the isolines of sound speed in the vertical cross section of the Strait along the sound pathway, based on the experimental data obtained by R/V Polarstern, and reflects the acoustic features of this region.

As is seen in Fig. 4, the larger spatial variations in sound speed on this pathway were observed in the upper layers of the ocean. The ocean inhomogeneities that lead to changes in sound speed can be assumed to vary randomly in time and space. The horizontal spatial scale of the sound speed inhomogeneity is on the order of $30 \mathrm{~km}$, and the sound speed can vary by $10 \mathrm{~m} \mathrm{~s}^{-1}$ at such a spatial scale. The environmental conditions at the eastern and the western part of the pathway are different. The West Spitsbergen current dominates at the region adjacent to Spitsbergen, and the East Greenland current dominates at the eastern part of the acoustic pathway (see Fig. 2).

Vertical profiles of sound speed, calculated at different points based on the measurements made by R/V Polarstern in March 1993, are presented in Fig. 6. These profiles were considered as initial steps to further calculations of the sound propagation in a variable environment. Then, two ensembles of sound speed distributions were constructed. One was obtained by shifting the sound speed field horizontally to simulate oceanographic variability and to numerically estimate the signal arrival-time fluctuations. Another set of profiles was constructed to model the ocean's surface-layer heating.

\subsection{Ocean Temperature-Increasing Model}

It was assumed that the temperature changes take place in the upper 200-m layer of the ocean. The corresponding sound speed variations were approximated as follows:

$$
\begin{aligned}
\frac{\Delta c}{c} & \simeq \alpha \Delta T, \\
\alpha & =\frac{3.09 \cdot 10^{-3}}{\mathrm{~K}},
\end{aligned}
$$

where $\Delta T$ is an ocean water temperature variation in kelvins, so $\Delta T=1 \mathrm{~K}$ corresponds to $4.51 \mathrm{~m} \mathrm{~s}^{-1}$ in sound speed variation at $c=1.46 \mathrm{~m} \mathrm{~s}^{-1}$. The variations in sound speed were added to the initial sound speed profiles (SSPs) in the upper 200-m subsurface layer: 


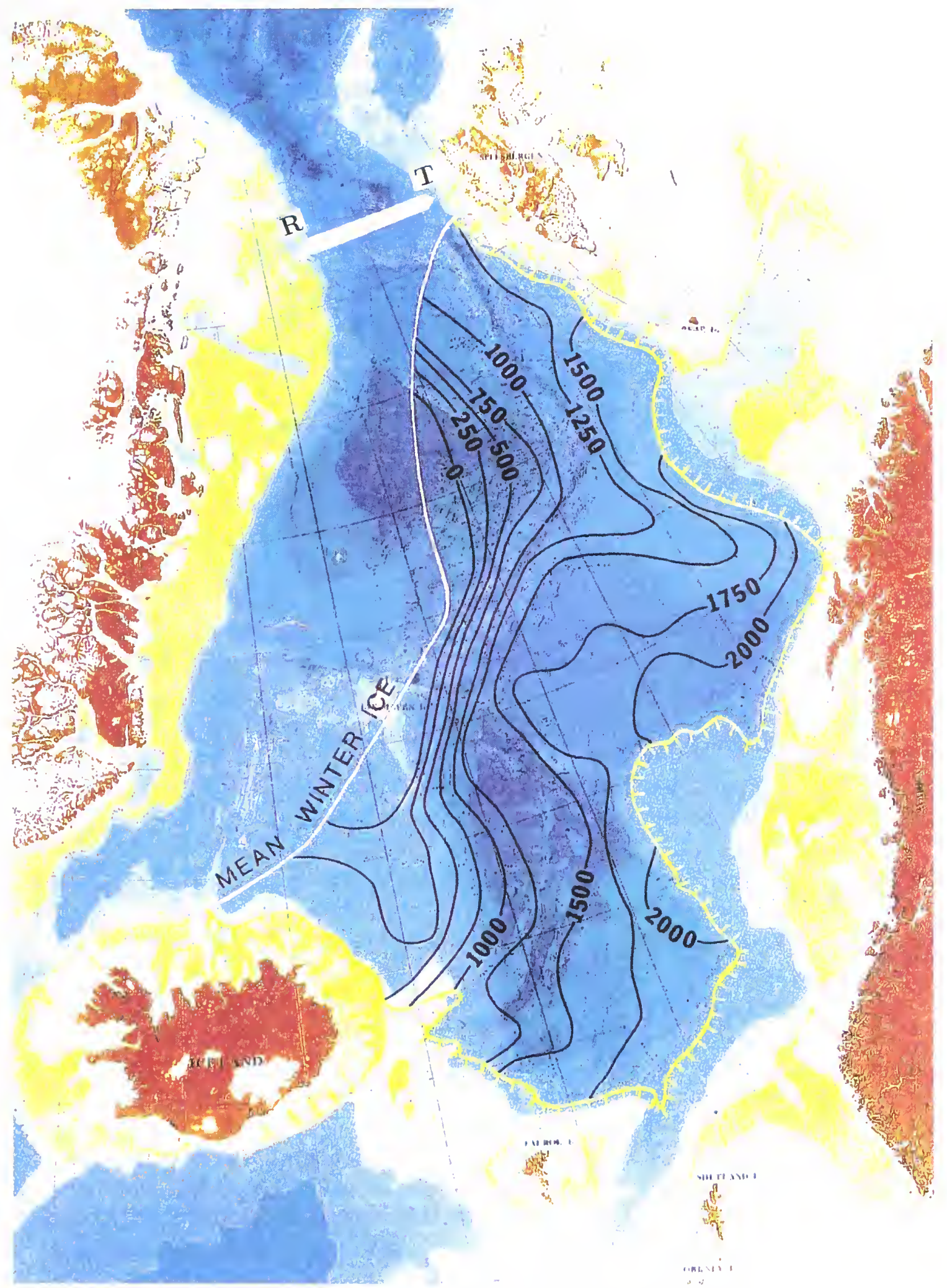

FIGURE 4. Regional bathymetry and sound speed channel depth (Hurdle, 1986), along with a suggested transmitter $(T)$ and receiver $(R)$ configuration for acoustic monitoring of volume and heat flux. 


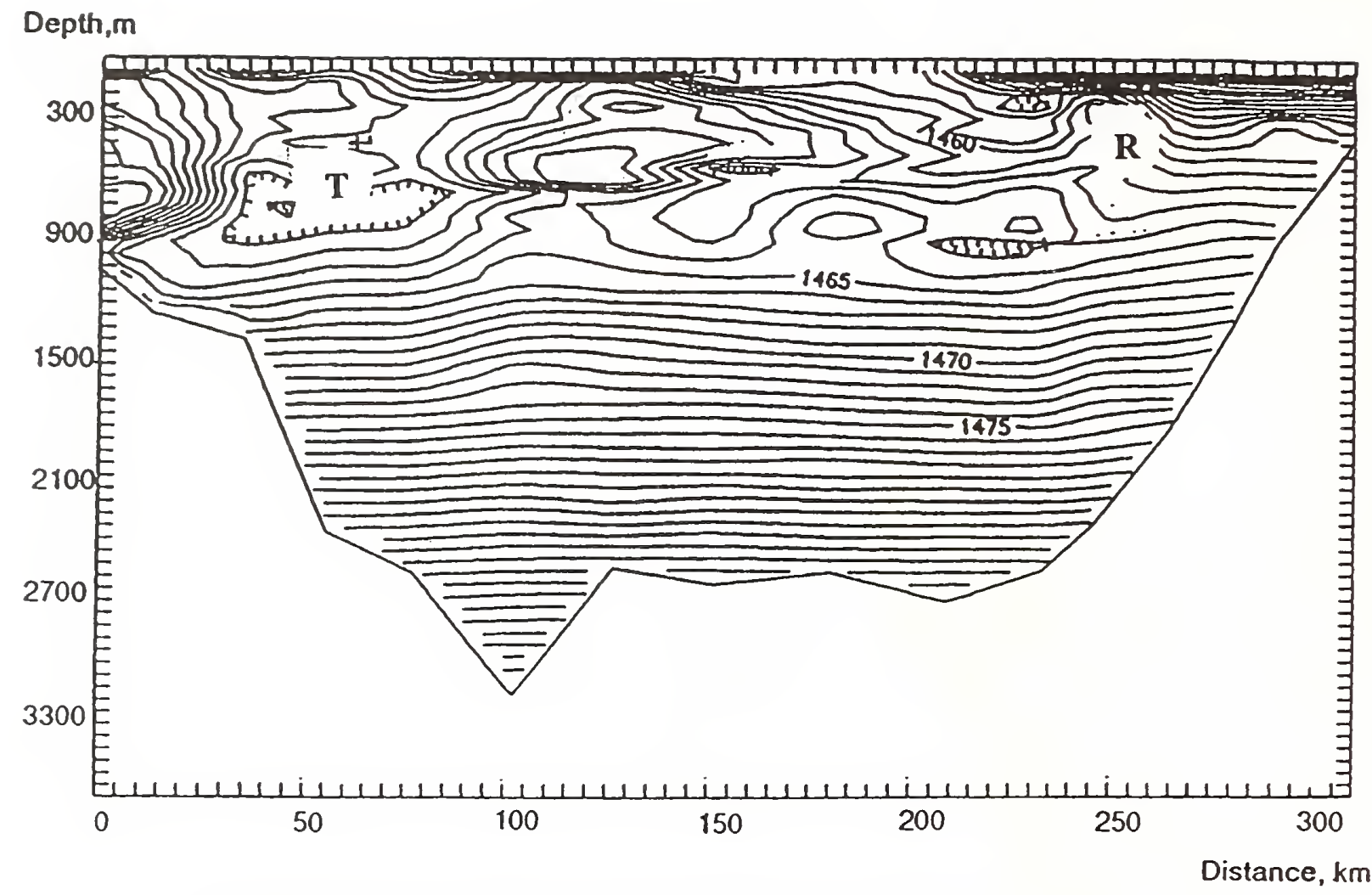

Figure 5. Sound speed isolines in the Fram Strait cross section.

SOUND SPEED PROFILES AT DIFFERENT CROSS SECTIONS OF THE TRACE

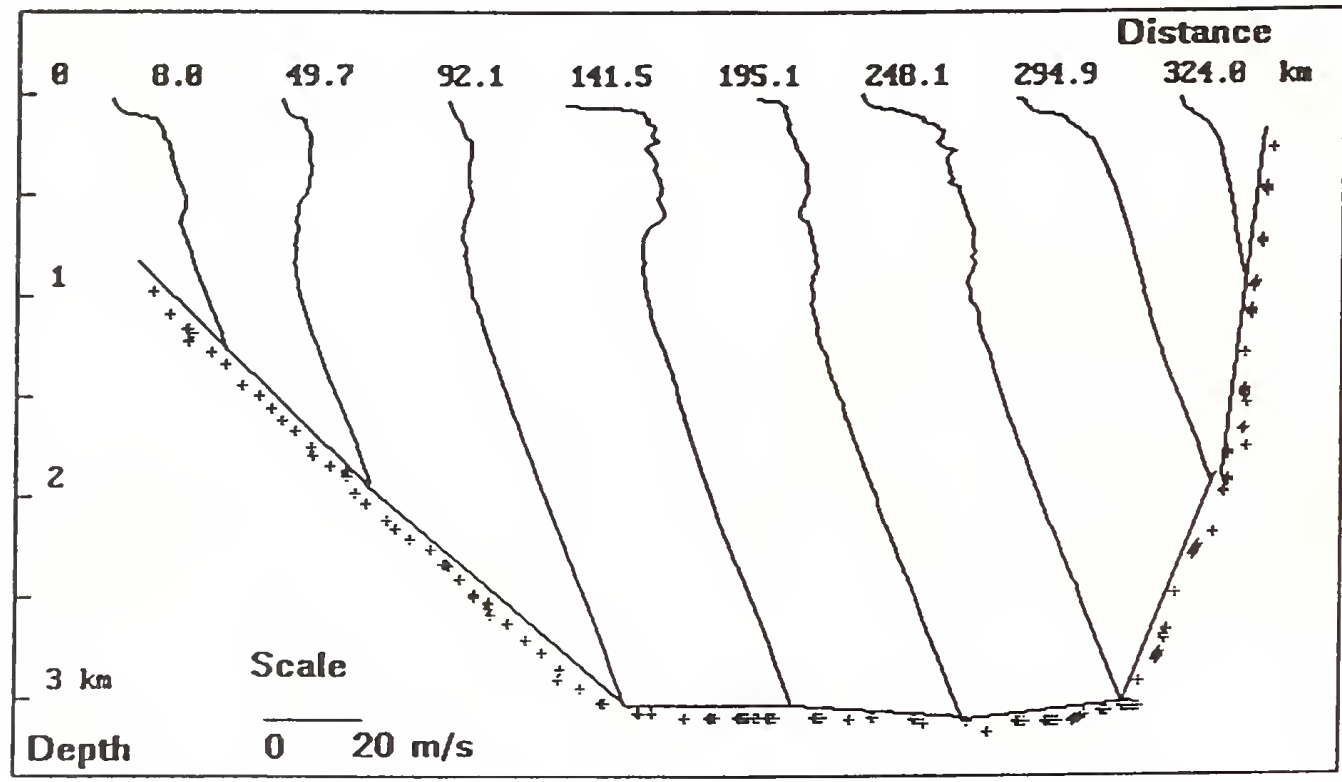

Figure 6. Sound speed profiles across the Fram Strait. 


$$
\begin{aligned}
\delta c & =\mathrm{DC} \exp \{-z / 200\}, \\
\mathrm{DC} & =4.5 \mathrm{~m} \mathrm{~s}^{-1} /{ }^{\circ} \mathrm{C} .
\end{aligned}
$$

The modified SSPs were obtained by exponential matching of the profiles obtained with the initial SSPs in the deeper layer of the ocean.

\section{ACOUSTIC PROPAGATION SIMULATION}

\subsection{Ray Arrival-Time Pattern}

Inversion of acoustical data is a reasonable way of remote sensing large-scale processes in the ocean interior. Variations of travel time are directly related to the ocean temperature averaged over a corresponding acoustic path. Using forward-backward measurements, one can also infer information about the average velocity component along the acoustic path. To infer the current velocity in a direction perpendicular to the acoustic path, the possible application of the scintillation method or horizontal refraction method should be investigated. Consider first the arrival-time variation due to ocean temperature change in the Fram Strait environment (Naugolnykh et al., 1997).

Statistical ensembles of the sound speed fields were constructed from specific parts of the general hydrographic data distribution presented in Fig. 5. The space between source and receiver forms a stationary path of $200-\mathrm{km}$ length. Ensembles of the signal travel times were obtained by shifting the entire sound speed pattern by $10 \mathrm{~km}$. In the course of computational modeling, 11 patterns of environmental conditions were considered. Thus, the total environmental shift in our modeling was $110 \mathrm{~km}$, which is essentially larger than the spatial scale of the inhomogeneities. This procedure can be used to randomize the travel time computation and determine fluctuations in signal arrival times that are due to ocean inhomogeneities.

The warming of the upper layer of the sea also affects acoustic signal travel time. For good travel time resolution, it is necessary to use broadband, high-frequency signals. To avoid excessive attenuation due to absorption and surface waves, the frequency should not be too high. In experiments using long paths in the ocean (more than $1000 \mathrm{~km}$ ), signals of several tens of hertz are used. The sound signal path in the Fram Strait is a few hundred kilometers long; therefore, signals with frequencies of several hundred hertz should be used. The sound field in this frequency range normally can be analyzed by ray representation. One can consider signal travel time as the propagation time along one of the rays between the transmitter and the receiver. If the depth of the transmitter and the receiver are appropriately chosen, the signal travel time along one or several rays can differ significantly from the travel time along other rays. Thus, if the signal frequency band is relatively broad, it is possible to separate the signals passing along the different rays by delay time. 
A numerical ray-tracing code was used to calculate the ray structure of the sound field. This provides the sound field level through both coherent and noncoherent summations of the sound signals propagating along different rays in the inhomogeneous ocean. The code takes into account spherical and cylindrical spreading, chemical absorption, surface and bottom effects, the sound wave attenuation in a homogeneous ocean, and anomalies of sound signal propagation due to inhomogeneities of the medium. At program input, the two-dimensional sound speed distribution in the ocean is given, and the positions of the sound source and receiver are specified. Propagation times for the sound signal along the pathway were calculated for different surface-layer temperatures. The amplitudes and arrival times of acoustic signals, propagating along different rays, vary as the environment changes. Stable rays sensitive to surface temperature variation were chosen for the simulations. One of them (ray 4s, Fig. 7) propagates initially downward and experiences four reflections; the other (ray 5s) propagates initially upward and has five contacts with the sea surface. Three receiver positions were considered at depths of $100\left(R_{1}\right), 200\left(R_{2}\right)$, and $300 \mathrm{~m}\left(\mathrm{R}_{3}\right)$, respectively.

The ray pattern is presented in Fig. 7 . The rays are presented for signal reception at levels of 100 and $300 \mathrm{~m}$. The variation of the hydrographic environment changes the ray paths and can lead to the disappearance of some of the rays. Ray $4 s$ at receiver $R_{1}$ is absent for the initial environmental condition; it appears after the first shift and disappears again on the fourth shift. For receiver $R_{3}$, ray $4 s$ disappears at the final shift. At all receivers, ray 4 s disappears at the fourstep shift to the right, while at the three-step shift, this ray disappears only at receivers $R_{1}$ and $R_{2}$. In all the other cases, this ray is stable.

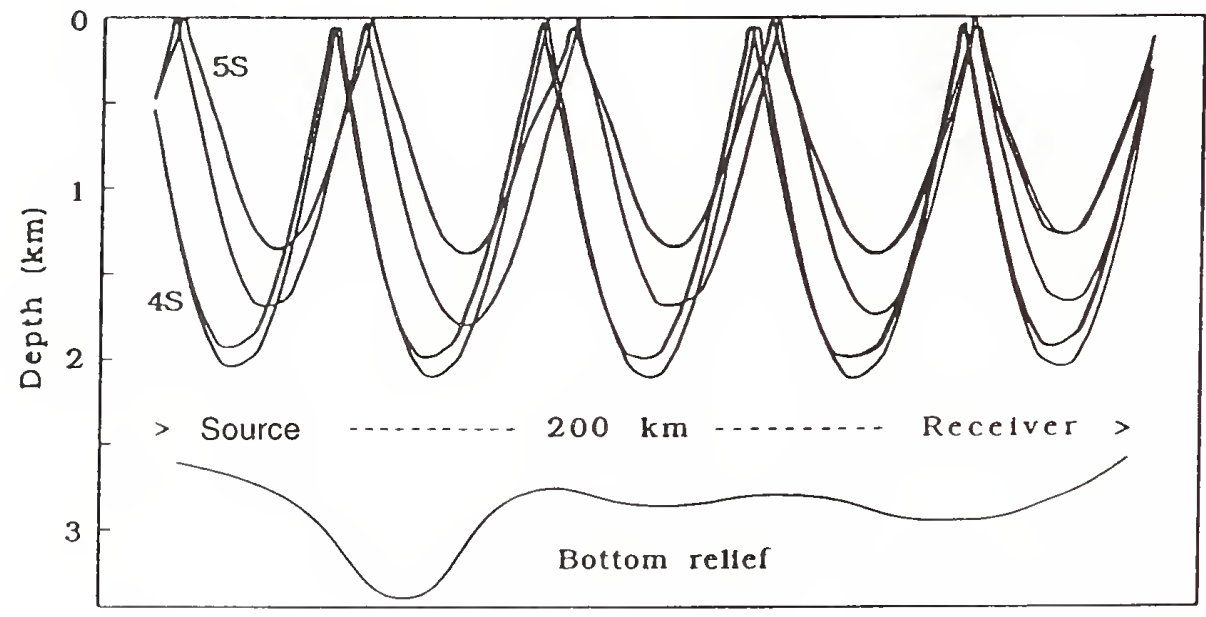

Figure 7. Paths of two rays along the trace. Ray 4 s contacted the sea surface four times; ray $5 \mathrm{~s}$ contacted the sea surface five times.

Table 2 shows the mean arrival times of signals propagated along ray $5 \mathrm{~s}$ for receivers placed at depths of 100,200 , and $300 \mathrm{~m}$, along with root-mean-square (rms) values of arrivaltime fluctuations averaged over 11 realizations. 
TABLE 2. Arrival Times of Signals

\begin{tabular}{ccc}
\hline $\begin{array}{c}\text { Receiver depth } \\
(\mathrm{m})\end{array}$ & $\begin{array}{c}\text { Ray 5s arrival times } \\
(\mathrm{s})\end{array}$ & $\begin{array}{c}\mathrm{rms} \\
(\mathrm{ms})\end{array}$ \\
\hline 100 & 137.02741 & 32.0 \\
200 & 137.01450 & 29.0 \\
300 & 137.00314 & 27.1 \\
\hline
\end{tabular}

Ray $5 \mathrm{~s}$ is emitted upward from the source. Table 2 demonstrates that arrival-time fluctuations along the moderately steep rays due to mesoscale inhomogeneities are on the order of $30 \mathrm{~ms}$. These fluctuations are easily measured, since the typical rms travel time uncertainty for these ranges is $1-2 \mathrm{~ms}$.

Travel times for sound signals propagating along different rays were calculated for the different temperatures of the upper 200-m subsurface layer. Typical results are given in Fig. 8, where the amplitudes and arrival times of the signal propagating along the different rays are presented. The mean arrival time variation with the temperature was calculated. It was obtained that travel time variation at $30 \mathrm{~ms}$ (which is equal to fluctuation rms) corresponds to a temperature change at $0.6^{\circ} \mathrm{C}$.

\subsection{Sensitivity of Cumulative Summation}

To detect the temperature trend against the random travel time fluctuations, we consider the cumulative sum with respect to the total train of arrival times, $t_{i}$, corresponding to the signal propagation along the different rays. When one arranges the signal arrival times in order of increasing value, $t_{1}<t_{2}<t_{3} \ldots<t_{N}$, the cumulative sum can be written as

$$
S(t)=\frac{1}{N}\left\{\begin{array}{ll}
0 & t<t_{1} \\
i & t_{i} \leq t<t_{i+1} \\
N & t>t_{N}
\end{array}\right\} .
$$

The normalization factor $1 / N$ is used to compare the results of the calculation for signal realizations with different numbers of rays. The cumulative sum computation procedure is as follows:

- The signal threshold is defined.

- The appropriate amplitude of the signal propagating along the chosen rays is normalized to 1 if its value is higher than the threshold; otherwise, it is set to 0 .

- The normalized amplitude of each successive signal is added to the sum of the normalized amplitudes of the preceding signals in order of signal arrival time.

- The total sum is normalized with respect to the number of terms in the series. 


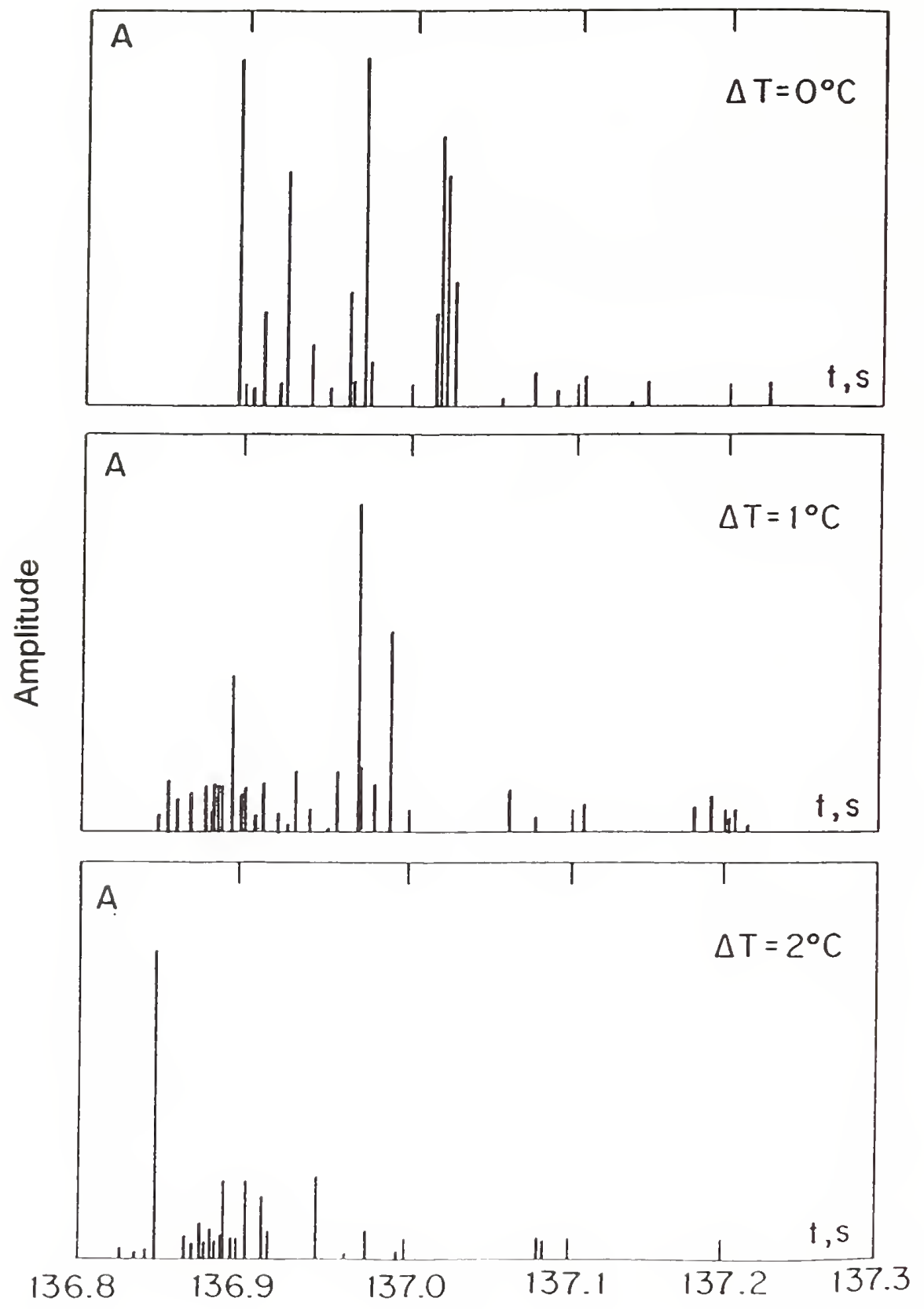

FIGURE 8. Signal amplitude and arrival-time dependance on the subsurface-layer temperature for different rays. Distance between transmitter and receiver is $200 \mathrm{~km}$; source depth, $500 \mathrm{~m}$; and receiver depth, $300 \mathrm{~m}$. 
The following analysis of the cumulative sum is based on the computation of the linear regression coefficients of $S(t)$ with respect to the time, $t_{i}$, of signal arrival. In other words, the coefficients $a$ and $b$ are defined for the expression $a t_{i}+b$, which gives the best approximation $S\left(t_{i}\right)$ in accordance with the least-squares method,

$$
\sum_{i=1}^{N}\left[S\left(t_{i}\right)-a t_{i}-b\right]^{2} .
$$

This procedure is outlined schematically in Figs. 9a-c, which shows the arrival signal pattern Fig. 9a), signals that exceed the threshold after amplification and limitation (Fig. 9b), and the cumulative sum (solid line, Fig. 9c) and the regression line (dotted line, Fig. 9c) as a function of time. Regression lines corresponding to different temperatures of the layer are presented in Fig. 10 as a function of signal arrival times. In Fig. 10, the labels indicate the subsurface-layer temperature increase, $\Delta T$ ( $\Delta T=0$ corresponds to the initial state of the environment), and the hydrographic pattern shift. So $(0 \mathrm{~K}, 0 \mathrm{~km})$ corresponds to the initial environment realization, $(0 \mathrm{~K}, 30 \mathrm{~km})$ corresponds to that shifted at $30 \mathrm{~km}$, and $(\Delta T \mathrm{~K}, 0 \mathrm{~km})$ corresponds to the realization with increased subsurface-layer temperature. The difference in slope of the lines corresponding to the initial environment realization and the realization that shifted at $30 \mathrm{~km}$ indicates the influence of background noise produced by mesoscale inhomogeneities. The other lines correspond to different degrees of warming of the upper surface layer. It can be seen from the plot that the slope of the lines increases as the temperature of the ocean's subsurface layers increases.
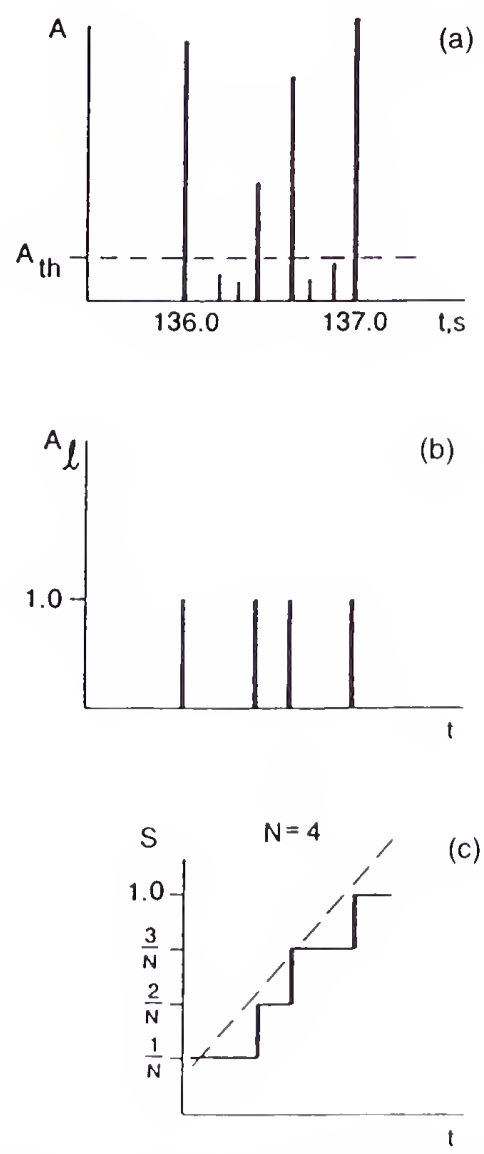

FIGURE 9. Cumulative sum derivation. (a) Arrival pattern; (b) signals exceeding the threshold, amplified and limited; (c) cumulative sum (solid line) and regression line (dotted line) as a function of time. 


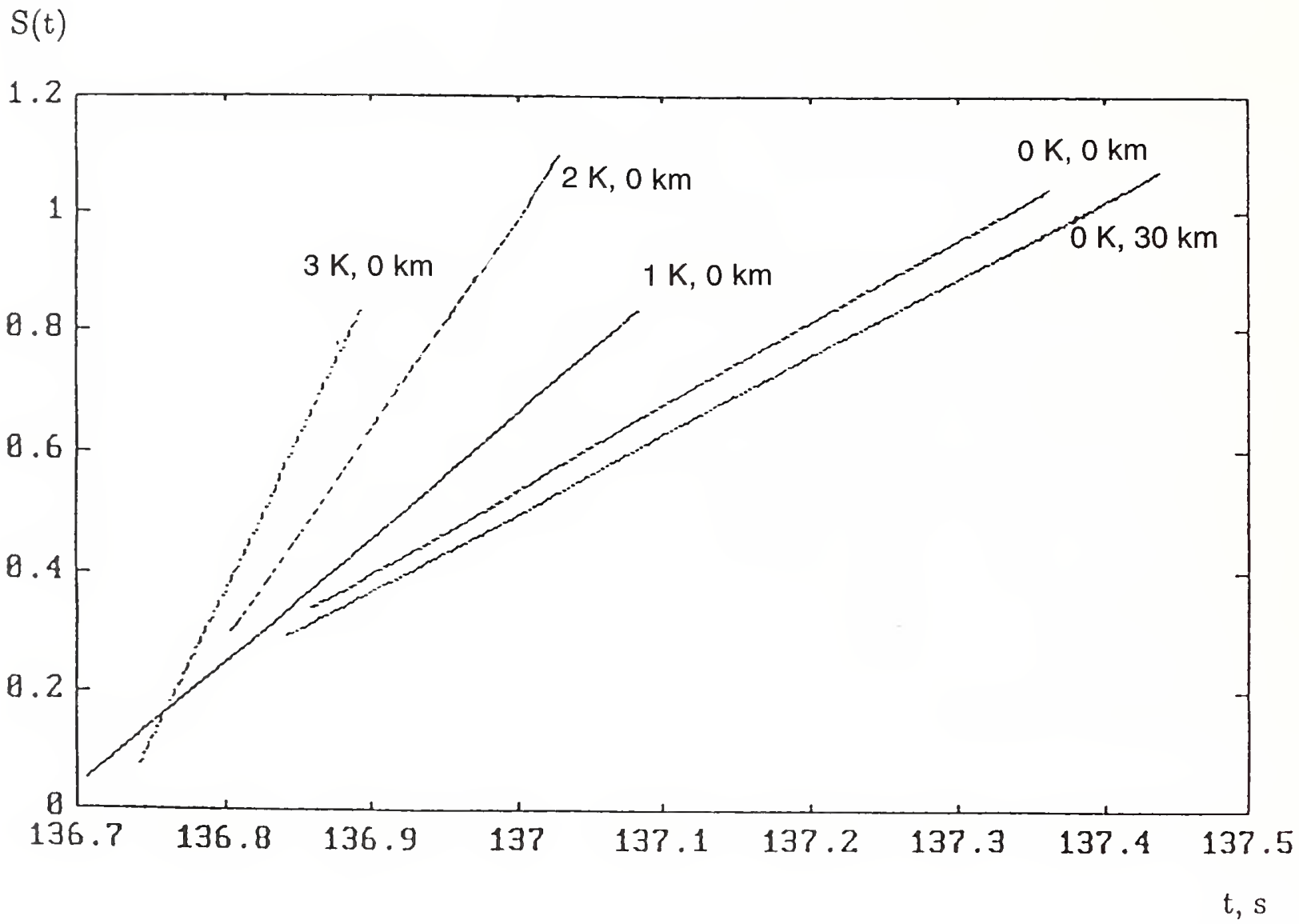

FIGURE 10. Cumulative sum regression lines versus signal arrival times for different subsurfacelayer temperatures. The subsurface-layer temperature increase, $\Delta T$ ( $\Delta T=0$ corresponds to the initial state of the ocean), and the hydrographic pattern shift are indicated.

\subsection{Strong Mode-Coupling Effect}

The modal approach was also used to calculate the sound signal arrivals (Shang et al., 1996). Numerical simulations have been conducted for the following four cases:

Case 1: Lower frequency $(f=20 \mathrm{~Hz})$, shallower source $\left(Z_{s}=50 \mathrm{~m}\right)$.

Case 2: Lower frequency $(f=20 \mathrm{~Hz})$, deeper source $\left(Z_{s}=200 \mathrm{~m}\right)$.

Case 3: Higher frequency $(f=200 \mathrm{~Hz})$, shallower source $\left(Z_{s}=50 \mathrm{~m}\right)$.

Case 4: Higher frequency $(f=200 \mathrm{~Hz})$, deeper source $\left(Z_{s}=200 \mathrm{~m}\right)$.

Results are presented in Table 3 and in Fig. 11. In Table 3, $A_{m}$ is signal amplitude; $t_{m}$ and $t_{m}^{\mathrm{Ad}}$ are the arrival times of the signals when the mode coupling effect was taken into account and in adiabatic approximation, respectively; and $T_{c}$ is the collective arrival time of the signals (see below). 
TABLE 3. Modal Travel Times for Case $1\left(f=20 \mathrm{~Hz}, Z_{s}=50 \mathrm{~m}\right)$ at 224-km Range

\begin{tabular}{|c|c|c|c|c|c|}
\hline & Mode & $A_{m}$ & $\begin{array}{r}t_{m} \\
(\mathrm{~s}) \\
\end{array}$ & $\begin{array}{l}t_{m}^{\mathrm{Ad}} \\
(\mathrm{s})\end{array}$ & $\begin{array}{l}T_{c} \\
\text { (s) }\end{array}$ \\
\hline $\mathrm{DC}=0 \mathrm{~m} \mathrm{~s}^{-1}$ & 1 & 0.80 & 153.245 & 153.243 & \\
\hline \multirow[t]{5}{*}{ (background) } & 2 & 1.0 & 153.245 & 153.217 & \\
\hline & 3 & 0.37 & 153.352 & 153.302 & \\
\hline & 4 & 0.42 & 153.474 & 153.327 & \\
\hline & 5 & 0.43 & 153.453 & 153.401 & \\
\hline & 6 & 0.98 & 153.503 & 153.472 & \\
\hline Collective: & & & & & 153.309 \\
\hline \multirow[t]{6}{*}{$\mathrm{DC}=4.5 \mathrm{~m} \mathrm{~s}^{-1}$} & 1 & 0.91 & 153.184 & 153.160 & \\
\hline & 2 & 0.71 & 153.145 & 153.122 & \\
\hline & 3 & 0.37 & 153.165 & 153.222 & \\
\hline & 4 & 0.62 & 153.349 & 153.252 & \\
\hline & 5 & 0.32 & 153.391 & 153.326 & \\
\hline & 6 & 1.0 & 153.453 & 153.419 & \\
\hline Collective: & & & & & 153.287 \\
\hline \multirow[t]{6}{*}{$\mathrm{DC}=9.0 \mathrm{~m} \mathrm{~s}^{-1}$} & 1 & 0.82 & 153.142 & 153.119 & \\
\hline & 2 & 0.66 & 153.088 & 153.072 & \\
\hline & 3 & 0.25 & 153.007 & 153.130 & \\
\hline & 4 & 0.59 & 153.275 & 153.185 & \\
\hline & 5 & 0.23 & 153.245 & 153.250 & \\
\hline & 6 & 1.0 & 153.399 & 153.358 & \\
\hline Collective: & & & & & 153.224 \\
\hline \multirow[t]{6}{*}{$\mathrm{DC}=13.5 \mathrm{~m} \mathrm{~s}^{-1}$} & 1 & 0.69 & 153.129 & 153.091 & \\
\hline & 2 & 0.57 & 153.074 & 153.046 & \\
\hline & 3 & 0.41 & 153.055 & 153.052 & \\
\hline & 4 & 0.40 & 153.244 & 153.119 & \\
\hline & 5 & 0.20 & 153.015 & 153.180 & \\
\hline & 6 & 1.0 & 153.336 & 153.290 & \\
\hline Collective: & & & & & 153.180 \\
\hline
\end{tabular}



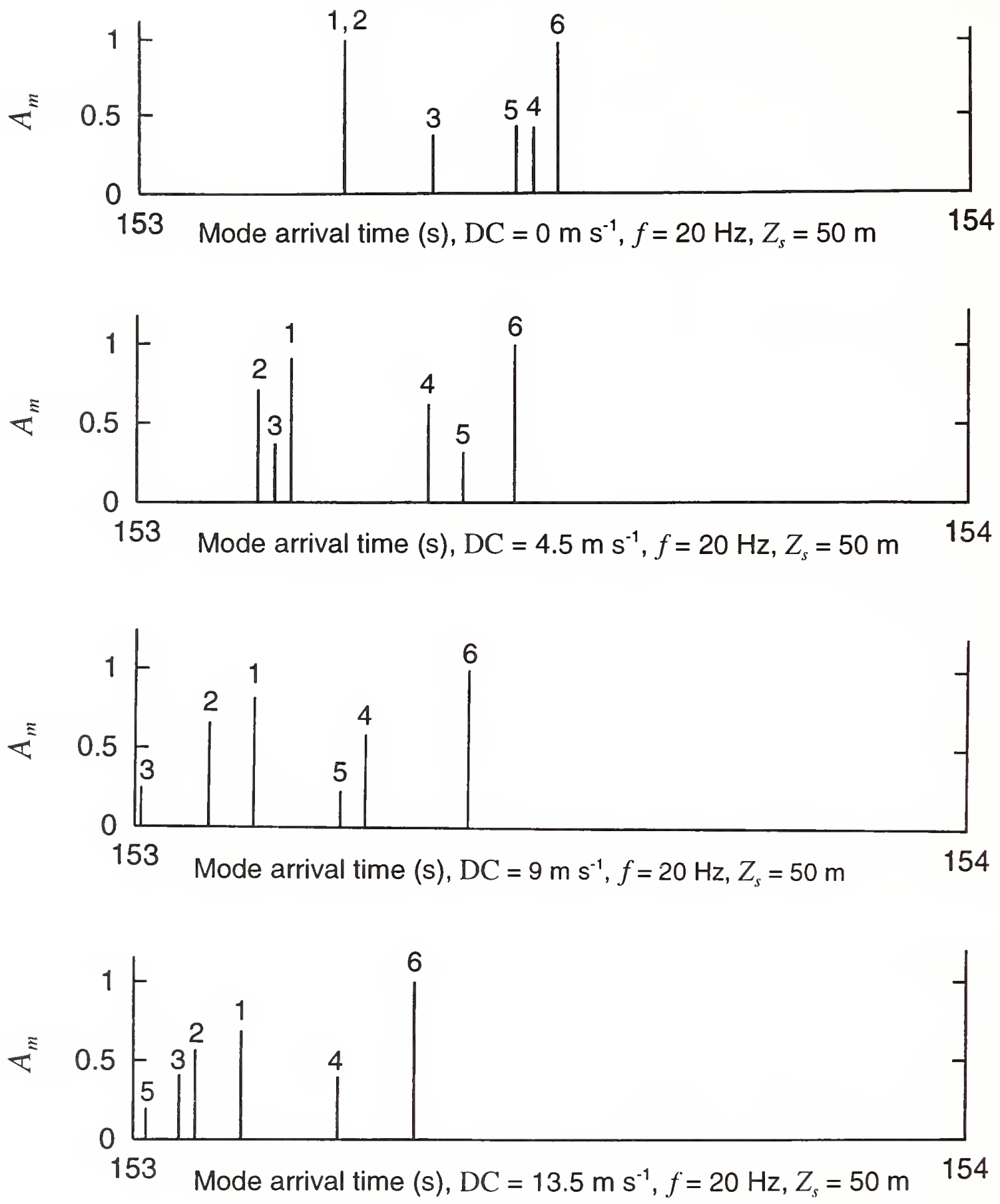

Figure 11. Modal arrival-time pattern for case 1 at 224-km range. Mode numbers are indicated above each line. 


\subsection{Sensitivity of Collective Arrival}

Strong mode coupling takes place along the propagation path (see Fig. 12). For this extremely complex propagation environment, the arrival times for a fixed mode sometimes will not have a monotonic relationship with the surface temperature increase. However, certain kinds of averaged arrival times could have a monotonic relationship with the surface temperature increase. Here, we propose the collective, or amplitude-weighted, arrival time, defined by

$$
T_{c}=\frac{\sum_{m}^{M} A_{m} t_{m}}{\sum_{m}^{M} A_{m}},
$$

where $A_{m}$ is the modal amplitude, $t_{m}$ is the arrival time, and $M$ is the maximum number of modes taken into account. The collective arrival time for case 1 is listed in the last column of Table 3. Figure 13 illustrates the relationship between collective arrival time and temperature increase for all four cases.

\subsection{Current Measurement}

To determine the velocity of flow across the acoustic pathway, the scintillation method can be used. A sound wave passing through the ocean's fine structure is modulated, producing an irregular pattern of amplitude and phase perturbations on some distant receiving plane. These perturbations are produced by medium changes. The evolution of the scintillation pattern occurs because of advection and decay of the ocean inhomogeneities. If the transit time of the scintillation pattern across the detector is short compared with eddy lifetimes, then the intervening transverse flow velocity can be estimated from the time delay of the correlation function of the signals propagating across the flow on the separate paths (Fig. 14; Clifford and Farmer, 1983; Crawford et al., 1990). Further investigations are needed to evaluate the feasibility of this method in application to a large distance such as the Fram Strait environment.

Another approach of transverse flow sounding is based on the horizontal refraction effect (Voronovich and Shang, 1995). Two vertical mode-resolving arrays should be used to receive signals propagating along separate paths. The phase difference of the modes at those two arrays is directly proportional to the value of the horizontal refraction caused by the horizontal gradient of the temperature and the transverse component of the current (Fig. 15). Conventional tomographic methods can determine current velocity along a vertical slice between two instruments. When combined with the corresponding temperature measurement, one can determine a path-averaged heat flux along the slice. For making volume and heat flux estimates in a strait, this may be of some help, but the method requires multiple instruments, essentially to map each field separately in a tomography mode. One possible method that is a hybrid point/ tomographic method would be to place multiple inverted echo sounders (MIES) across the Strait in a zig-zag pattern to measure local current, temperature, and fluxes; these could be combined with pressure and horizontal electric field sensors to provide additional data. 


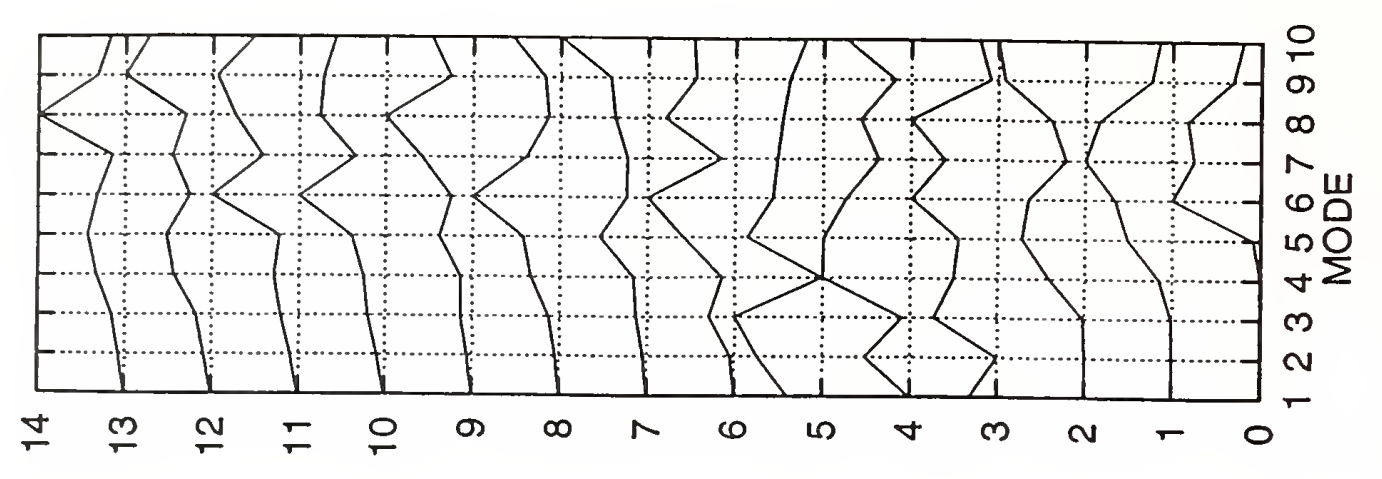

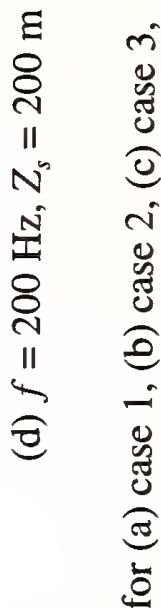

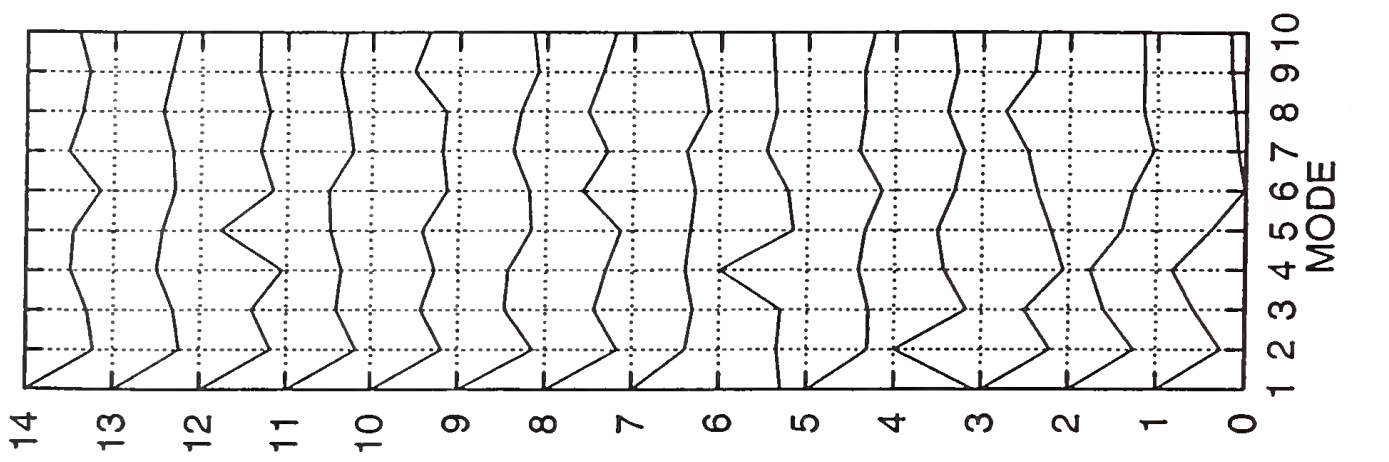

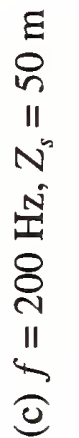

导

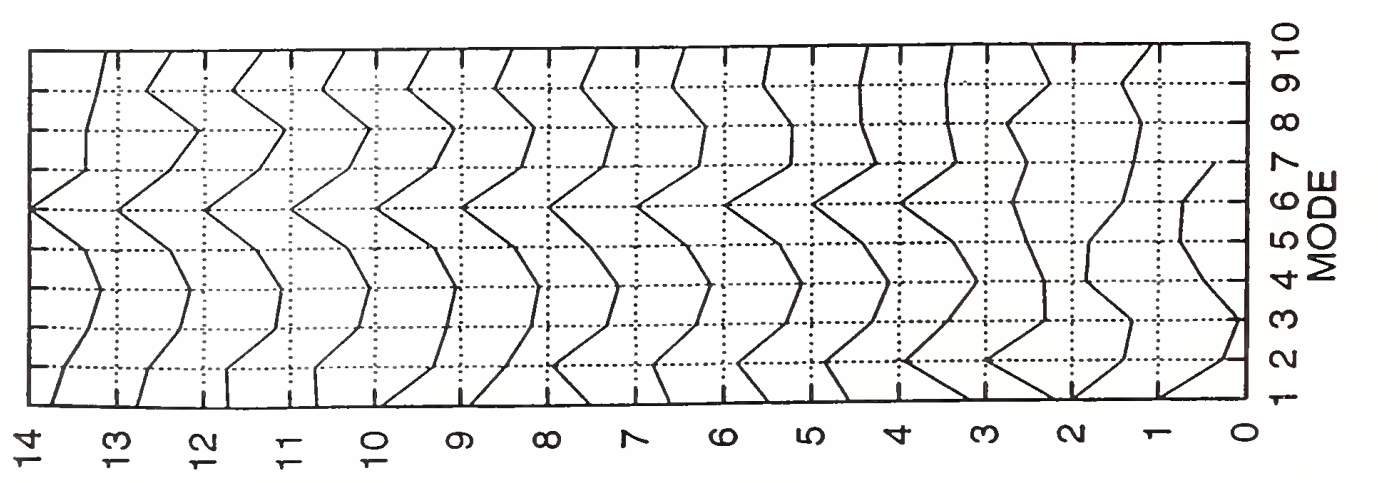

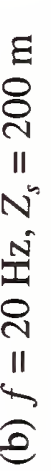

पे

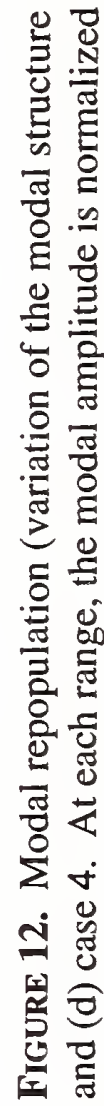
$\exists פ N \forall Y$ 


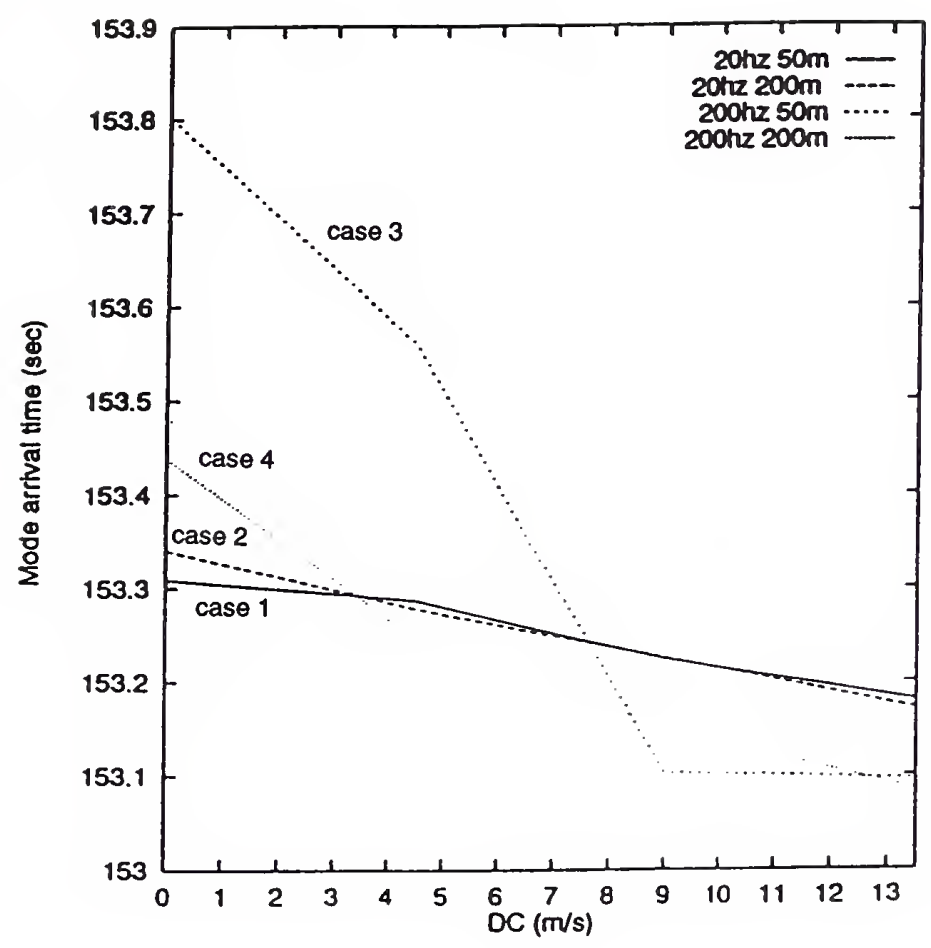

FigurE 13. The collective arrival time versus the surface temperature increase for cases $1-4$.
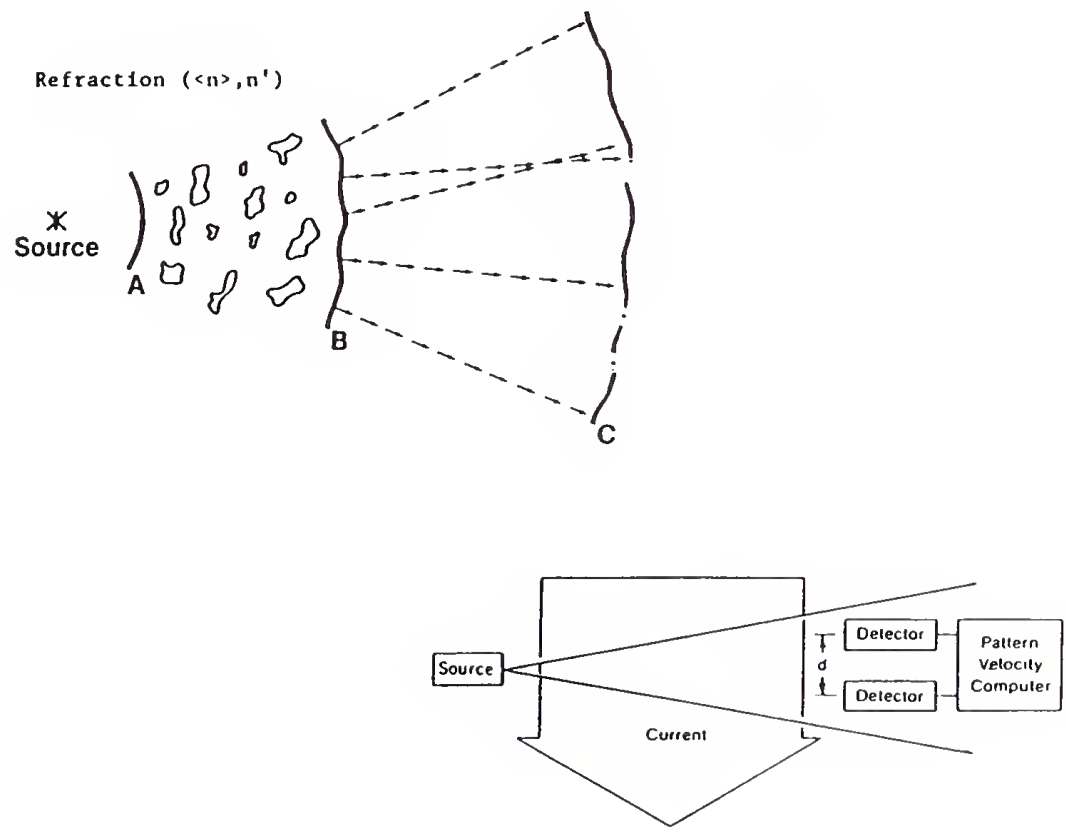

FIGURE 14. Ocean current measured by acoustic scintillation. 

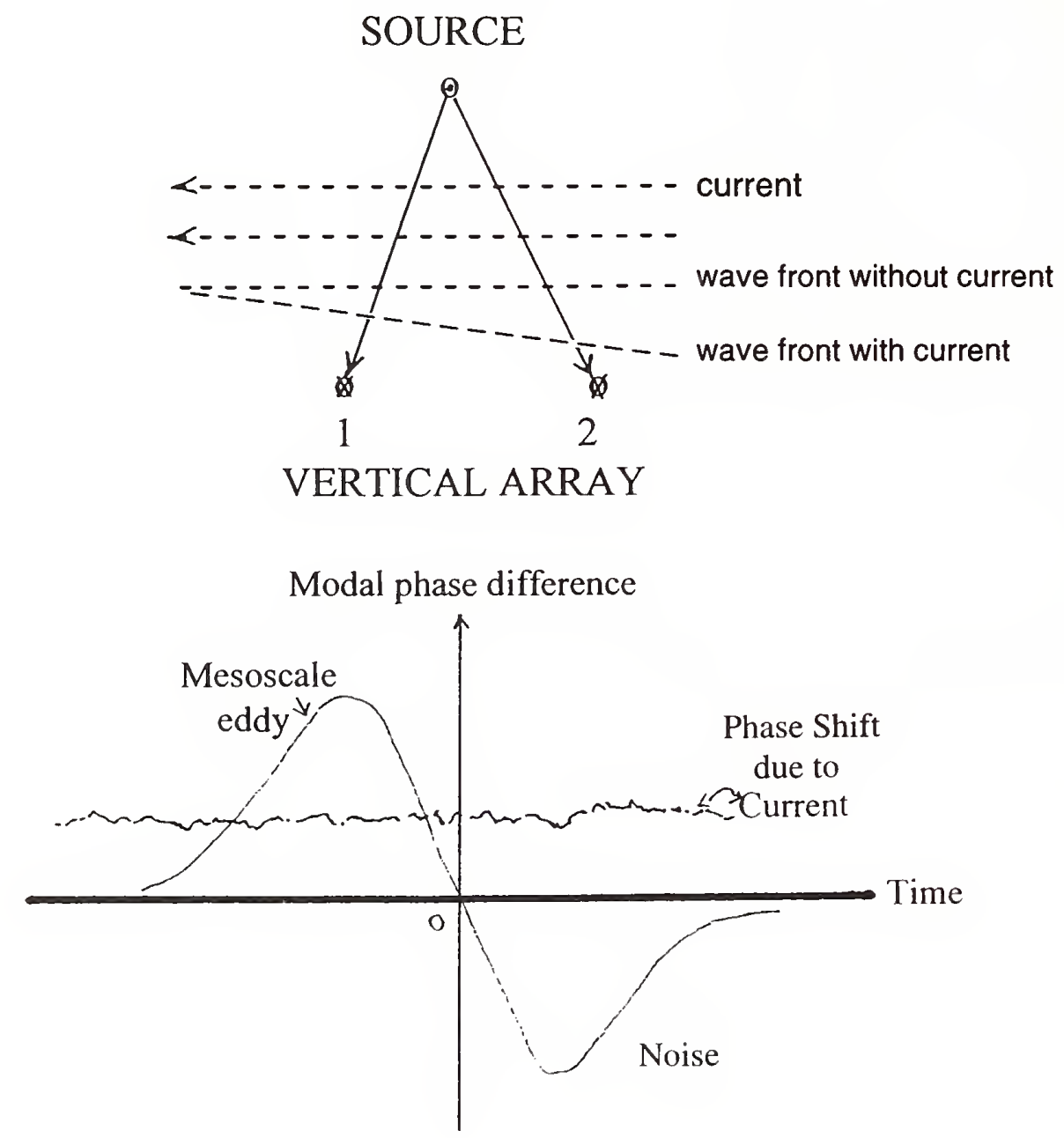

FIGURE 15. Ocean current measured by horizontal refraction tomography. 


\section{PARAMETRIC ARRAY AS A MODE-SELECTIVE SOURCE}

The sound propagation in a complex environment such as the Fram Strait is characterized by strong mode coupling, which leads to mode repopulation (variation of the modal structure of a sound field with distance). The arrival-time pattern varies in a complicated manner, and the arrival times for a fixed mode sometimes will not have a monotonic relationship with the subsurface-layer temperature increase. The application of a parametric array (PA) could be useful in this case. A parametric array, suggested by Westervelt (1963), is based on the nonlinear effects of sound generation as a result of interaction at a high-frequency wave. Recent experiments demonstrated the efficiency of a PA for ocean probing (Andebura et al., 1990). The main feature of the PA is to produce a narrow-beam, broad-frequency-band, sharply directed radiation (Andebura et al., 1990) that could be used for selective mode excitation in a stratified ocean. Some results of simulation of a PA application for the Fram Strait sounding are presented in the following figures. In Fig. 16, the modal structure of the sound field for different orientation of the PA is presented; $\theta$ is the angle between the axis of the PA and the horizon. The sound field intensity distribution for different inclinations of the PA axis in comparison to that produced by a point source are given in Figs. 17-19. It is seen that application of the PA allows sensing of different depth intervals of the ocean. In Fig. 20, the collective arrival time as a function of the ocean temperature increase is presented for a point source and for the PA having different orientations (the inclination of the PA axis with respect to the horizon). This figure demonstrates that the PA provides more sensitive probing of ocean temperature increases. The PA sound field features could also be used for current measurements (Dmitriev and Naugolnykh, 1994).

\section{CONCEPT OF STUDY}

\subsection{Numerical Modeling}

An acoustic monitoring system for the Fram Strait will necessarily be based on an inversion scheme using measured travel times, intensity, mode structure, and refraction angles to obtain temperature and the current field and, thereby, the heat and volume flux through the Strait. To establish the inversion scheme, it is necessary to have prior information available about the Strait and feasible acoustic propagation models. Inversion schemes are built upon a theoretical and numerical acoustic propagation model; the accuracy of the inversion result depends on the accuracy of the forward model. Therefore, our first goal is to do computer modeling of signal travel time variation with respect to water temperature and current using the acoustic tomography and scintillation approach, in order to monitor the volume and heat flux through the Fram Strait. Following the computer modeling, the pilot experiment will be performed. 
重

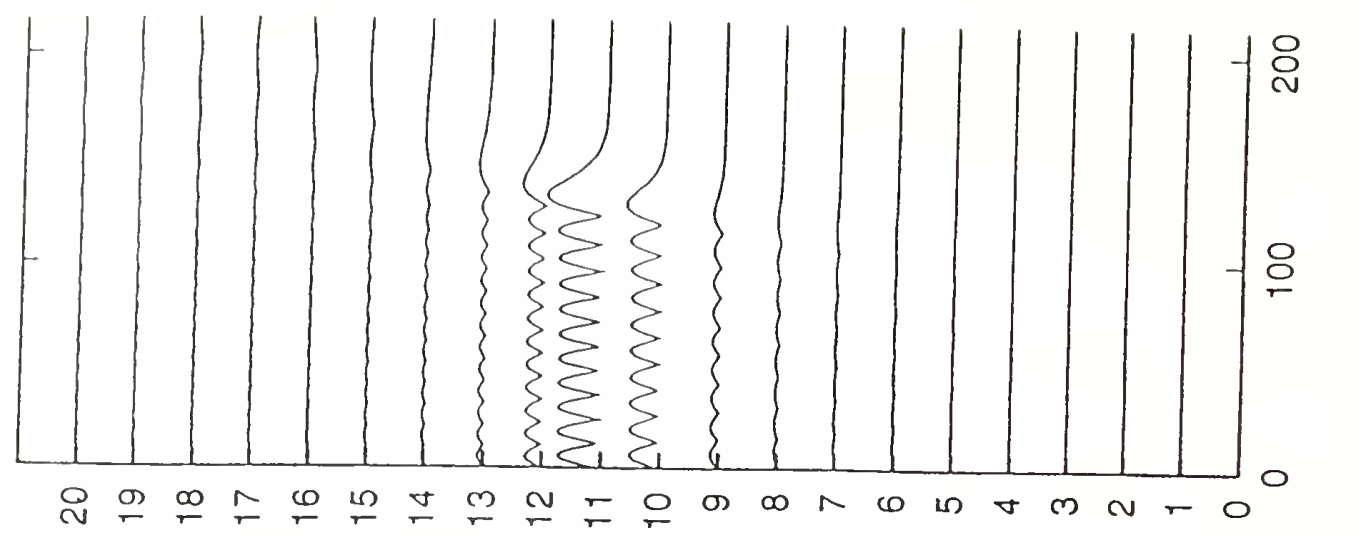

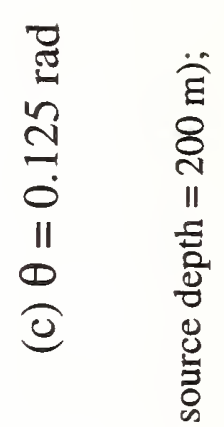

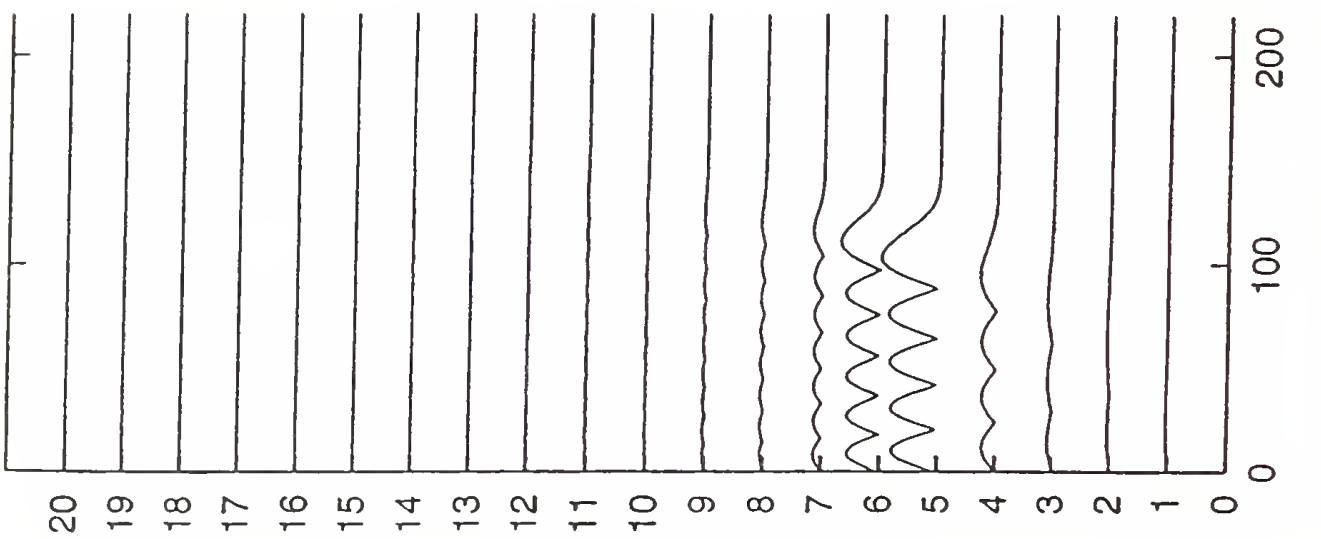

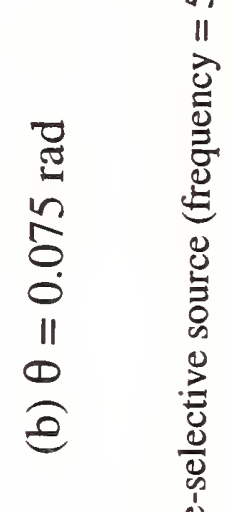

N

8

岁

gั

촣을

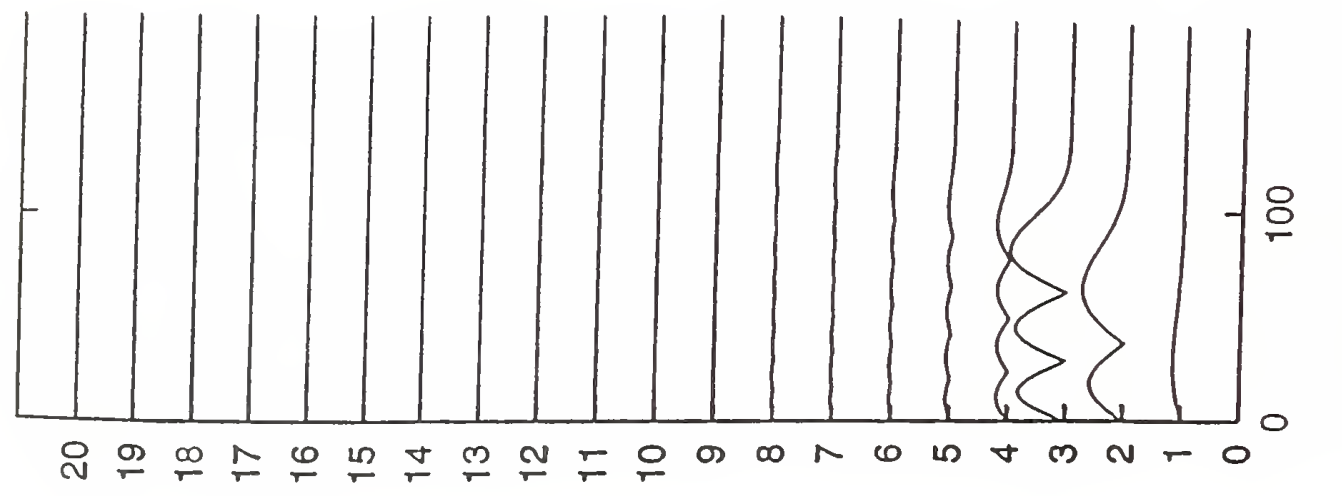

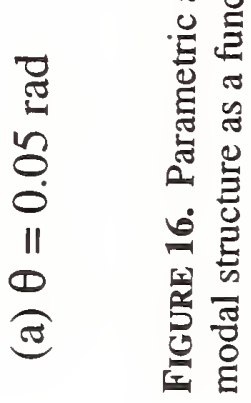

y $\exists$ gWnN $\exists ロ O W$ 


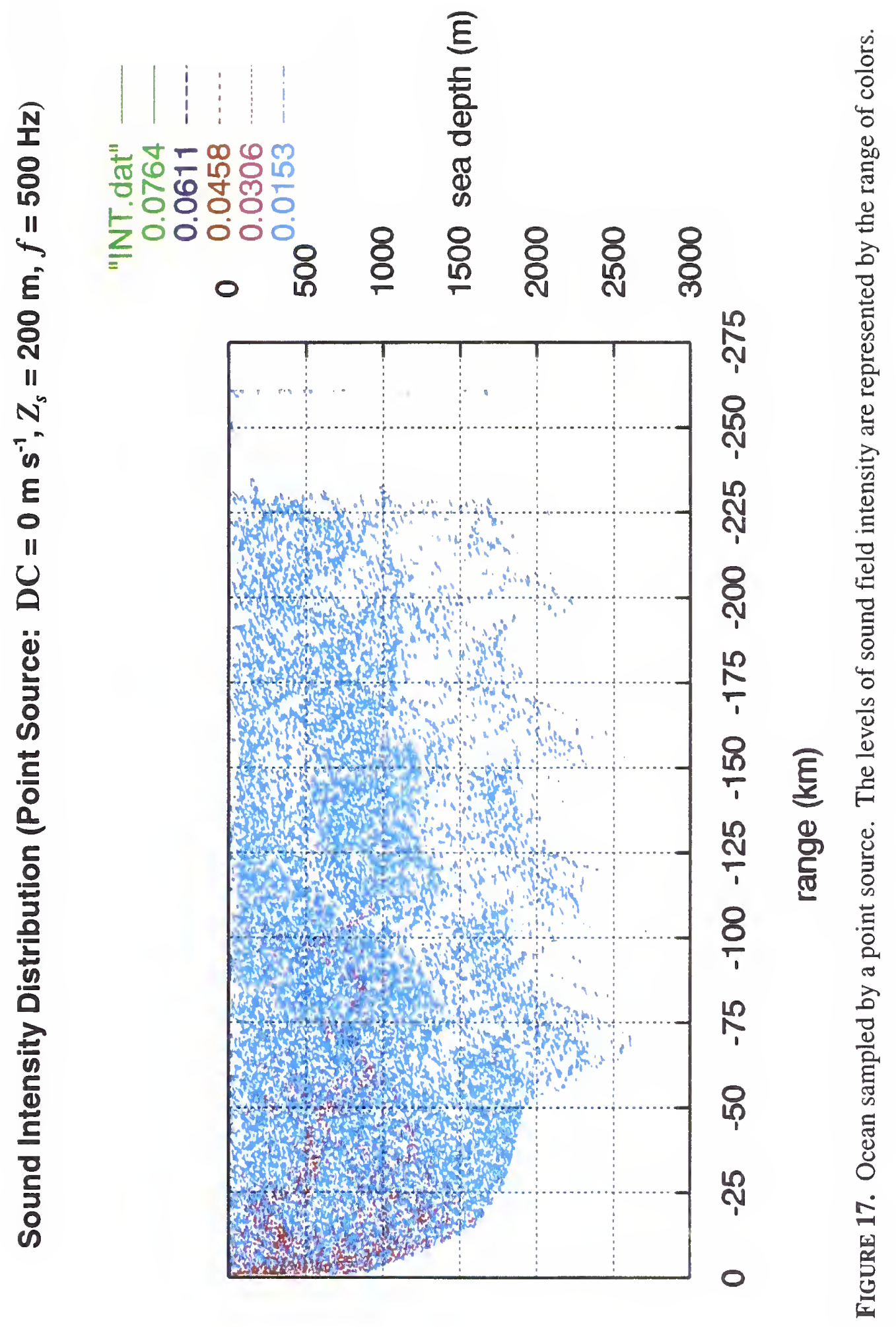




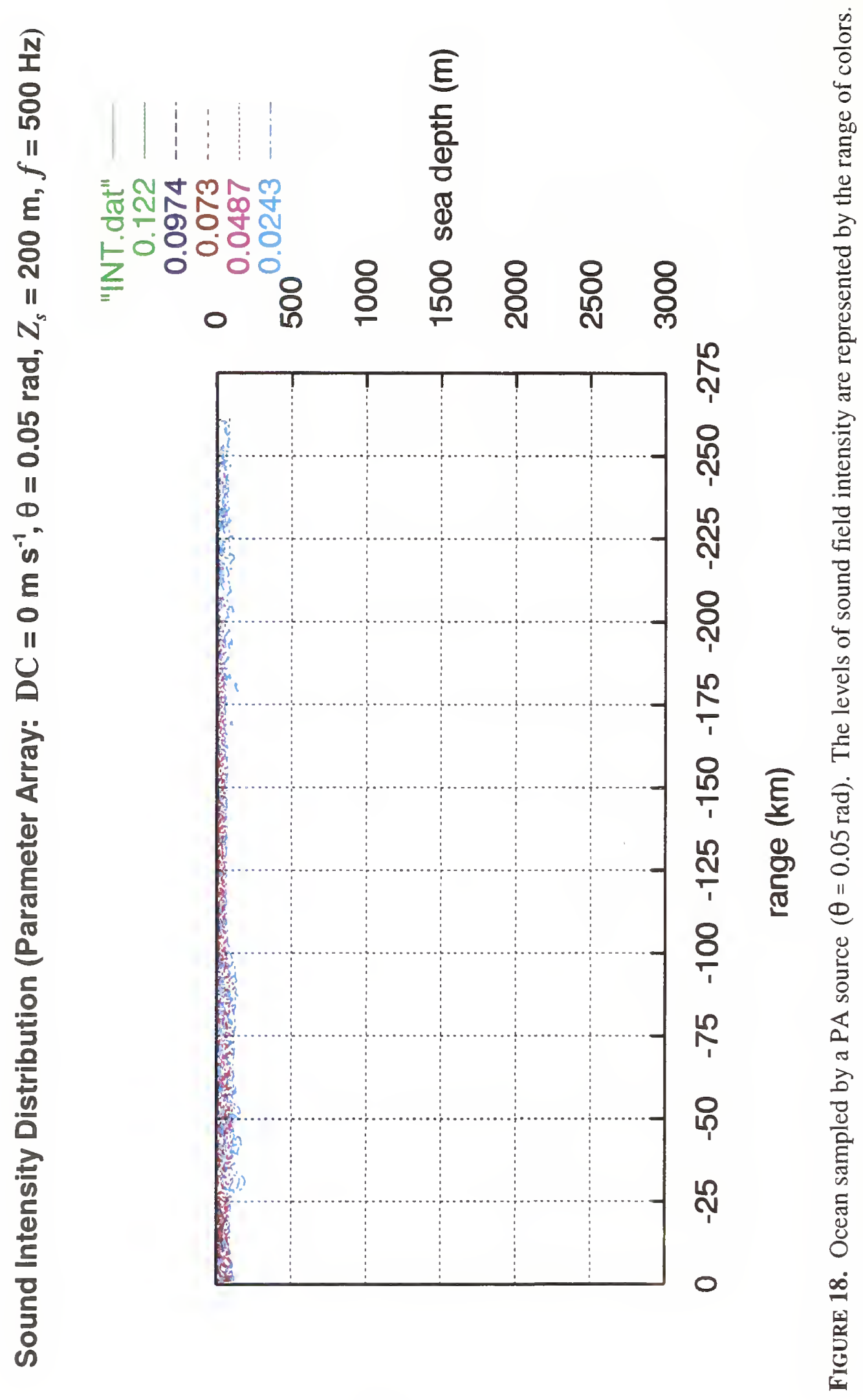




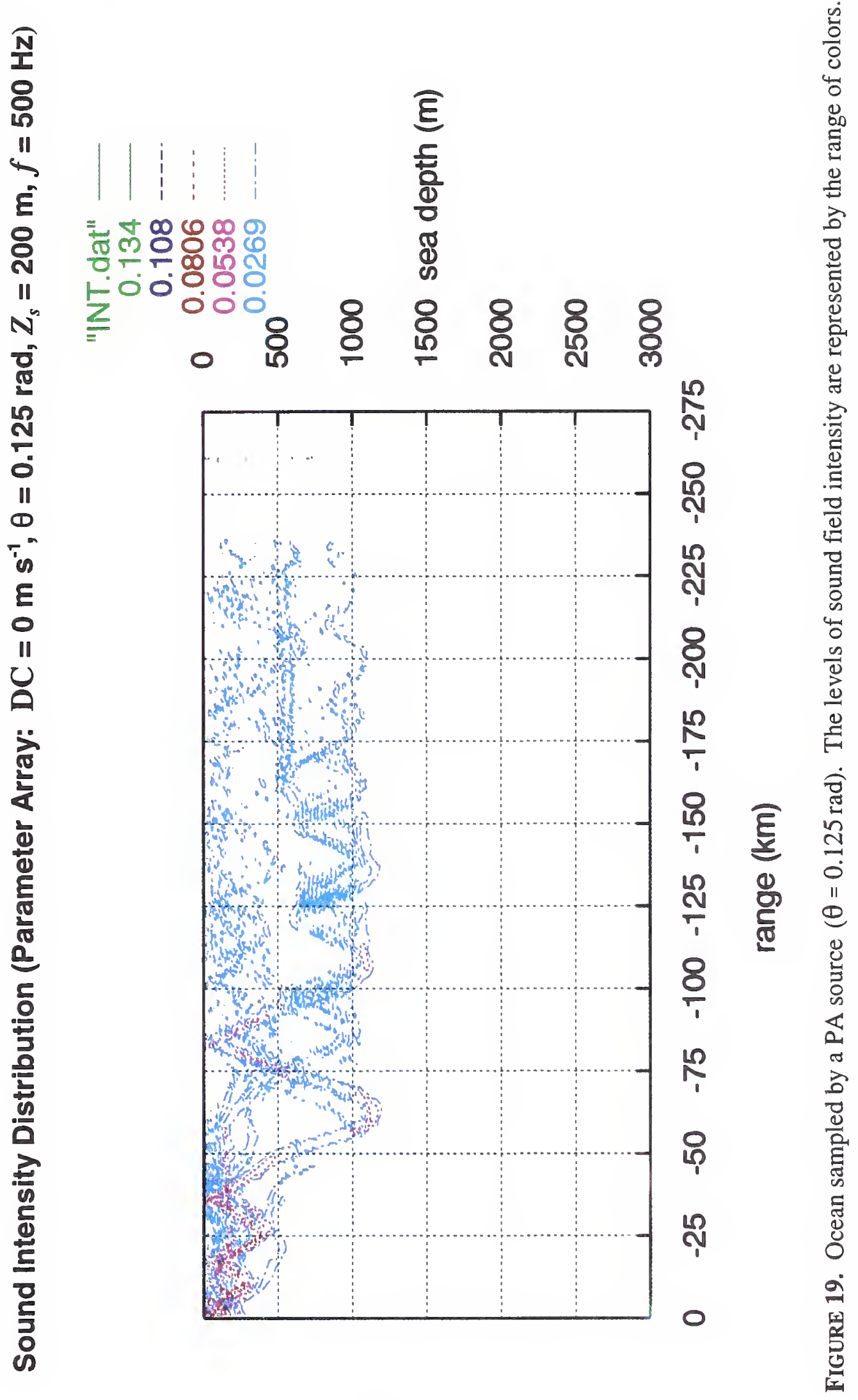




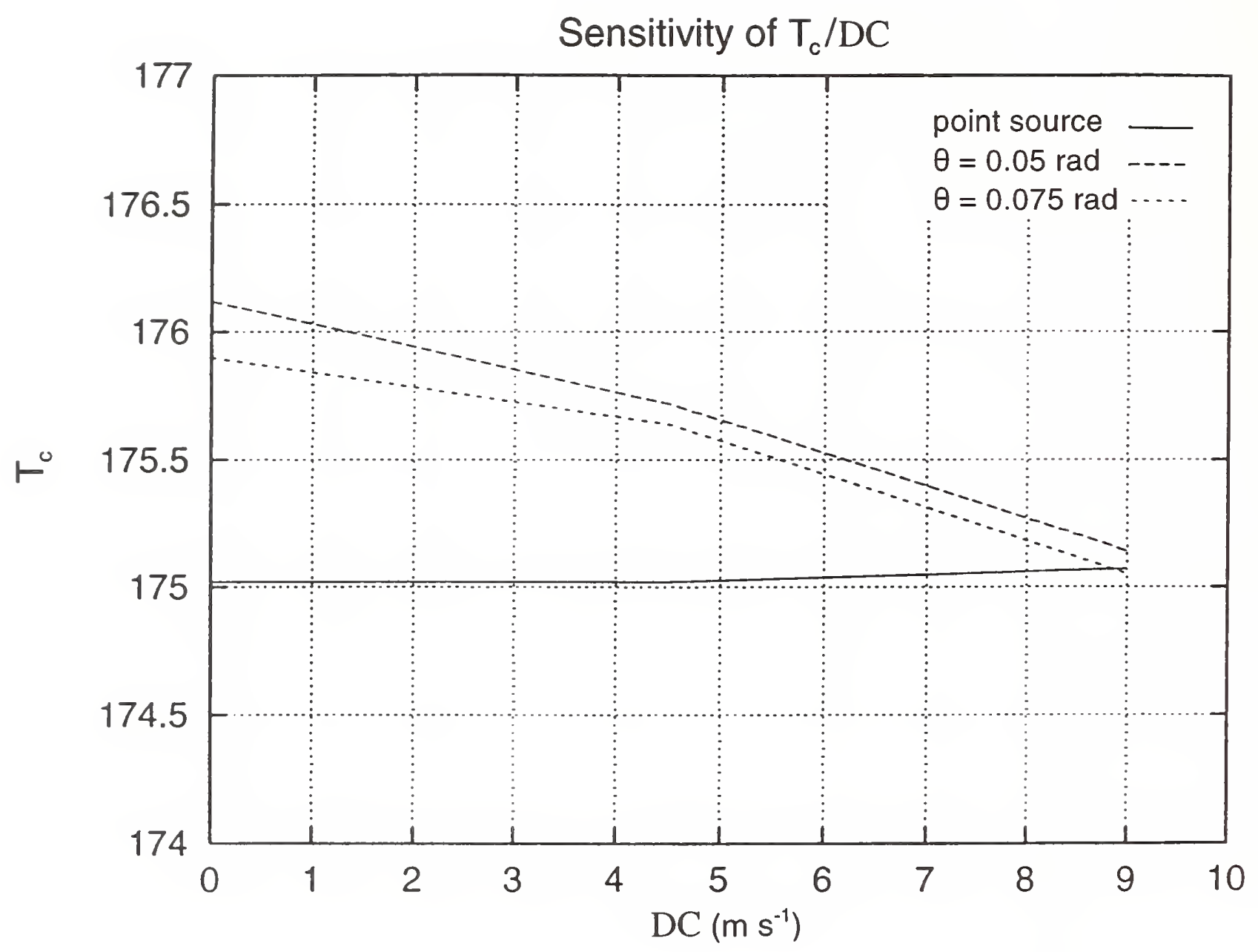

Figure 20. Sensitivity comparison $\left(f=500 \mathrm{~Hz} ; Z_{s}=200 \mathrm{~m}\right)$. 


\subsubsection{Physical oceanographic data}

Physical oceanographic data would best be made available as a small database on an FTP site. Particularly useful data for our planning would be Atlantic/Arctic waterfront characteristics, mesoscale eddy field characteristics, internal wave field characteristics, and ice cover characteristics. In using the oceanography, the best product would be $T, S$, and $(u, v)$ as functions of $(x, y, z, t)$, where $t$ includes seasonal effects. Sound speeds are easily obtained from these. Also useful to our efforts would be the exact bathymetry, bottom geoacoustic properties, coastal front characteristics, and the typical wind and wave fields.

\subsubsection{Forward propagation modeling}

First consider some of the system's characteristics. Assume that the system's point sources will be at $250 \mathrm{~Hz}$, with a $100-\mathrm{Hz}$ bandwidth, and will generate 192-dB source level initially. (This is typical of HLF-5s, which were used very successfully in the Greenland Sea.) Also, assume that vertical line array receivers are located at the shallow eastern (Svalbard) part of the system (at minimum) and probably are positioned at all source locations. This array will nominally span the water column. Further, assume that computer storage of data at the receiver is not an issue, since disk storage is very efficient these days. Unless we use cabled systems, these sources and receivers will have limited duration; therefore, temporal sampling strategies would need to be considered. The adequacy of the signal strength received and the stability and identifiability of the arrivals will also need to be considered. Additional points to address are (1) the ice scattering and surface wave rough surface effects, (2) bottom interaction use of bottom interacting signals, (3) travel time perturbations expected due to temperature effects, (4) reciprocal travel time signals expected due to current effects, (5) scintillation signals expected due to advection of structure through the tomographic path, and (6) horizontal refraction effects due to currents.

\subsubsection{Inverse problem}

At least three inverses for the proposal are (1) a cumulative inverse; (2) a conventional tomography inverse for $T, u, v$, together with resolution and variance estimates; and (3) a rudimentary scintillation inverse for fluxes. Additional forward modeling and inverse schemes have to be considered: more sophisticated range-dependent rays, coupled modes, and parabolic equation calculations for forward modeling, as well as horizontal ray refraction, S-matrix, and single-mode generation schemes for inversion work.

\subsubsection{Observing system simulation experiments}

In the long term, one will want to combine the results of measurement with ocean general circulation models to obtain the best overall estimate of the four-dimensional state of the ocean (Evensen, 1994a,b). The data would consist not only of the acoustic observation that has been the primary subject of this report, but other complementary information that may be available, 
such as the results of satellite observations or from cable voltages. Observing system simulation experiments (OSSES) must be performed to determine what is the best mix of the different measurement techniques. Some of the possible questions that need to be addressed are (1) what resolution is required in the vicinity of the different fronts and at other locations; (2) how well is the true turbulent heat flux measured (if, for instance, the velocity and temperature are measured along a path or over an area); (3) how many degrees of freedom are necessary to describe the flow; (4) what are the correlation length and time scales; etc.

\subsection{Pilot Experiment}

\subsubsection{Objectives}

The specific objectives of the pilot experiment are (1) perform scientific studies on the feasibility of a permanent monitoring of the Atlantic water and heat inflow through the Fram Strait; (2) demonstrate the efficacy of a combined acoustics/conventional sensor system for heat flux measurements; (3) obtain a full year of oceanographic data to initiate the monitoring effort; (4) test some novel concepts in acoustic monitoring, which may allow improvement of the system; and (5) establish requirements for needed technical equipment for long-term monitoring.

\section{Proposed tasks are:}

Task 1. Computer modeling of signal travel time variation with respect to water temperature and current variations using archival oceanographic data as input.

Task 2. Develop an experimental scheme for a feasibility demonstration of remote acoustic monitoring of heat and mass transfer through the ocean current cross section based on an acoustic scintillation approach.

Task 3. Perform a pilot experiment to measure the travel time variation and scintillation of signals crossing the Fram Strait; obtain experimental verification of the principles of S-matrix heat monitoring (a new approach).

Task 4. Analyze the experimental results and develop recommendations for permanent remote acoustic monitoring of heat and mass transfer through the Fram Strait into the Arctic Ocean.

\subsubsection{Methods of investigation}

Different methods for acoustic monitoring of temperature and velocity of current through the Fram Strait will be used. For the basic acoustic array, three modified Avatoc transceivers (A1, A2, and A3) and one DOAR vertical-line-array (VLA) receiver will be used. The array is shown in Fig. 21. The two eastern receivers will allow a year-long time series to be obtained for (1) standard temperature tomography; (2) reciprocal current measurements (A1 to A3, A2 to A3, 


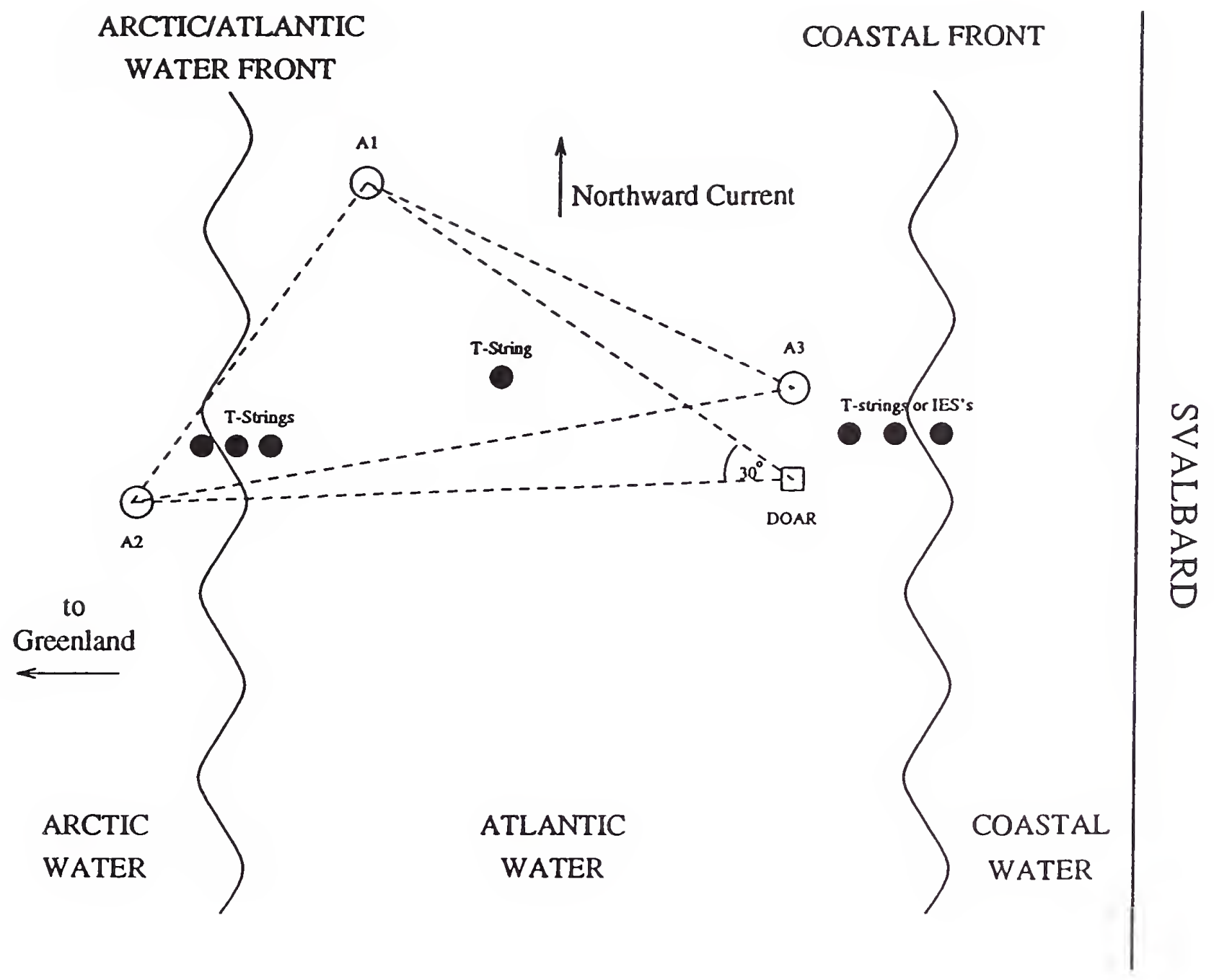

Figure 21. Possible pilot experiment array. 
and $\mathrm{A} 1$ to $\mathrm{A} 2$ ); (3) scintillation measurements (A1 to A3/DOAR and A2 to A3/DOAR); and (4) horizontal refraction measurements (A1 to A3/DOAR and A2 to A3/DOAR). Some number of conventional oceanographic sensors are needed both to aid the acoustics interpretation and to provide data for the overall inverse. To help look at temperature near the fronts, whose east-west movement across our acoustic paths is critical, T-strings, inverted echo sounders, and satellite remote sensing will be used. The acoustic Doppler current profilers (ADCPs), the temperature and conductivity gage (Seacats), and the temperature measuring strings (T-strings), all located on the acoustic moorings and halfway across the A1-to-A3 path, help provide supplementary flux measurements to verify tomographic measurements and help with the acoustic propagation analyses. The array will be deployed in late summer, during which time the shipborne sources and other instrumentation to test the various flux-measuring, inverse schemes proposed will be used. This deployment cruise would last 2-3 weeks, most likely. It would need at least a medium-sized vessel accommodating a science party of approximately 10-12 people. The basic array of sensors would be left in the water over the next year and recovered the next summer. In order to test the novel inverse schemes in a timely fashion, we would have to transfer data from the A1 and A3 transceivers and the DOAR array directly after the pilot experiment.

\subsubsection{Expected results and the project period}

Expected results of the project are the experimental comparison of the efficiency of different methods of acoustical monitoring in variable environments typical of the Fram Strait; the performance of a feasibility test of the combined acoustic-conventional system for heat flux measurements; a full year of oceanographic data for the Fram Strait environment; and the original data to design an optimal, acoustical measuring system for sensing of volume transport and heat flux through the Fram Strait.

\section{CONCLUSION}

What is the specific problem? Greenhouse warming in the Arctic is expected to be two to four times greater than that in lower latitudes. If this happens, it could significantly raise global sea levels. The water mass and heat exchange through the Fram Strait are essential boundary conditions for global climate models. Previous estimates of the current flux of the West Spitsbergen current across $79^{\circ} \mathrm{N}$ vary from 1.9 to $8 \mathrm{~S}_{\mathrm{v}}$. This large variation in water mass exchange introduces errors in ocean circulation and global climate models.

What are we doing? An acoustic monitoring scheme is being designed that will transmit low-frequency sound across the Strait to measure average temperature, and scintillation techniques will measure the transverse current. Combining the two measurements gives an estimate of heat flux. Propagation modeling, already under way, shows the acoustic environment to be very complex, with strong mode coupling. A parametric array could be used to obtain fine depth resolution, and the low acoustic power in a required low-frequency range will make the measurement "whale safe." 
What is the payoff? Improved measurements of Arctic warming will reduce the uncertainty in the global warming models. Data assimilation taken during the Fram Strait monitoring will provide an essential contribution to the ATOC-Arctic project and will contribute to a reduction in the uncertainty in the modeling and prediction of global climate warming.

\section{REFERENCES}

Aagaard, K., and E. Carmack, 1994: The Arctic Ocean and climate: A perspective. In The Polar Oceans and Their Role in Shaping the Global Environment. AGU Geophysical Monograph 85, 5-20.

Aagaard, K., and P. Greisman, 1975: Toward new mass and heat budgets for the Arctic Ocean. J. Geophys. Res. 80, 3821-3827.

Andebura, V. N., D. M. Donskoy, K. A. Naugolnykh, Yu. S. Stepanov, and A. M. Sutin, 1990: Sound field at a high-power radiator in parametric operation. Sov. Phys. Acous. 36(3), 305-306.

Cattle, H., and J. Crossley, 1995: Modeling Arctic climate change. Philos. Trans. Roy. Soc. London A 352, 201-213.

Clifford, S., and D. Farmer, 1983: Ocean flow measurements using acoustic scintillation. J. Acous. Soc. Am. 74(6), 1826-1832.

Cornuelle, B. D., and B. M. Howe, 1987: High spatial resolution in vertical slice ocean acoustic tomography. J. Geophys. Res. 92, 11,680-11,692.

Cornuelle, B. D., C. Wunsch, D. Behringer, T. G. Birdsall, M. Brown, R. Heinmiller, R. A. Knox, K. Metzger, W. H. Munk, J. L. Spiesberger, R. C. Spindel, D. Webb, and P. F. Worcester, 1985: Tomographic maps of the ocean mesoscale, 1: Pure acoustics. J. Phys. Oceanogr. $15,133-152$.

Crawford, G., R. Lataitis, and S. Clifford, 1990: Remote sensing of ocean flows by spatial filtering of acoustic scintillations: Theory. J. Acous. Soc. Am. 88(1), 442-454.

Cubasch, U., G. Hegerl, A. Hellbach, H. Höck, U. Mikolajewicz, B. D. Santer, and R. Voss, 1995: A climate change simulation starting at an early time of industrialization. Climate Dyn. 11, 71-84.

Dmitriev, V. G., and K. A. Naugolnykh, 1994: The parametric transmitter field in a wave guide with a smoothly inhomogeneous liquid flow. Acous. Phys. 40(3), 347-350.

Dushaw, B. D., G. D. Egbert, P. F. Worcester, B. D. Cornuelle, B. M. Howe, and K. Metzger, 1997: A TOPEX/Poseidon global tidal model (TPXO.2) and barotropic tidal currents determined from long-range acoustic transmissions. Prog. Oceanogr., in press.

Evensen, G., 1994a: Inverse methods and data assimilation in nonlinear models. Physica D 77, 108-129.

Evensen, G., 1994b: Sequential data assimilation with a nonlinear quasi-geostrophic model using Monte Carlo methods to forecast error statistics. J. Geophys. Res. 99, 10,143-10,162.

Farmer, D. M., and D. Di Iorio, 1996: Two-dimensional angle-of-arrival fluctuations. J. Acous. Soc. Am. 100(2), pt. 1, 814-824.

Hasselmann, K., 1993: Optimal fingerprints for the detection of time-dependent climate change. J. Climate 6, 1957-1971. 
Heard Island Papers, 1994: J. Acous. Soc. Am. (Special Issue) 96(4), 2327-2484.

Hurdle, B. G., 1986: The Nordic Seas. Springer-Verlag, New York, 777 pp.

IPCC (Intergovernmental Panel on Climate Change), 1996a: Climate Change 1995: The Science of Climate Change. Contribution of Working Group I to the Second Assessment Report of the Intergovernmental Panel on Climate Change (J. J. Houghton, L. G. Meiro, B. A. Callander, N. Harris, A. Kattenberg, and K. Maskell, Eds.). Cambridge University Press, $584 \mathrm{pp}$.

IPCC (Intergovernmental Panel on Climate Change), 1996b: Climate Change 1995: Impacts, Adaptations, and Mitigation of Climate Change: Scientific Technical Analyses.

Contribution of Working Group II to the Second Assessment Report of the Intergovernmental Panel on Climate Change (R. T. Watson, M. C. Zinyowera, and R. H. Moss, Eds.). Cambridge University Press, 880 pp.

IPCC (Intergovernmental Panel on Climate Change), 1996c: Climate Change 1995: Economic and Social Dimensions of Climate Change. Contribution of Working Group III to the Second Assessment Report of the Intergovernmental Panel on Climate Change (J. Bruce, Hoesung Lee, and E. Haites, Eds.). Cambridge University Press, 608 pp.

Jin, G., J. F. Lynch, R. Pawlowicz, and P. Wadhams, 1993: Effects of sea ice cover on acoustic ray travel times, with applications to the Greenland Sea tomography experiment. J. Acous. Soc. Am. 94, 1044-1057.

Jin, G., J. F. Lynch, R. Pawlowicz, and P. Worcester, 1994: Acoustic scattering losses in the Greenland Sea marginal ice zone during the 1988-1989 tomography experiment. J. Acous. Soc. Am. 96, pt. 1, 3045-3053.

Johannessen, O. M., M. W. Miles, and E. Bjørgo, 1995a: The Arctic's shrinking sea ice. Nature 376, 126-127.

Johannessen, O. M., M. W. Miles, and E. Bjørgo, 1995b: Time series analysis of SMMR and SSMI data for climate change detection. Proceedings of IGARSS 95, Firenze, Italy, July 10-14, 1995, 625-626.

Johannessen, O. M., E. Bjørgo, and M. W. Miles, 1996: Global warming and the Arctic. Science 271, p. 129.

Luther, D. S., J. H. Filloux, and A. D. Chave, 1991: Low-frequency, motion induced electromagnetic fields in the ocean. 2. Electric field and Eulerian current comparison. J. Geophys. Res. 96, 12,797-12,814.

Macdonald, R., 1996: Awakenings in the Arctic. Nature 380, 286-287.

Manabe, S., R. J. Stouffer, M. J. Spelman, and K. Bryan, 1991: Transient responses of a coupled ocean-atmosphere model to gradual changes of atmospheric $\mathrm{CO}_{2}$. Part I: Annual mean responses. J. Climate $4(8), 785-818$.

Mikhalevsky, P. N., A. B. Baggeroer, A. N. Gavrilov, and M. Slavinsky, 1994: Continuous wave and M-sequence transmission across the Arctic. J. Acous. Soc. Am. 96(5), pt. 2, p. 3235.

Mikhalevsky, P. N., A. N. Gavrilov, and A. B. Baggeroer, 1995: Are faster than predicted arrival times seeing Arctic Ocean warming? J. Acous. Soc. Am. 97, p. 3234.

Mitchell, J., T. Johne, J. Gregory, and S. Tett, 1995: Climate response to increasing levels of greenhouse gases and sulfate aerosols. Nature 357, 501-504. 
Munk, W., 1994: Acoustic remote sensing. In The Polar Oceans and Their Role in Shaping the Global Environment. AGU Geophysical Monograph 85, The Nansen Centennial Volume, 521-524.

Munk, W. H., and A. M. G. Forbes, 1989: Global ocean warming: An acoustic measure? J. Phys. Oceanogr. 19(11), 1765-1778.

Munk, W. H., R. Spindel, A. Baggeroer, and T. Birdcall, 1994: The Heard Island Feasibility Test. J. Acous. Soc. Am., 96(4), 2330-2342.

Munk, W., P. Worcester, and C. Wunsch, 1995: Ocean Acoustic Tomography. Cambridge University Press, Cambridge Monographs on Mechanics, UK, 433 pp.

Naugolnykh, K. A., O. M. Johannessen, I. B. Esipov, O. B. Ovchinnikov, Yu. Tuzhilkin, and V. V. Zosimov, 1997: Numerical simulation of remote acoustic sensing of ocean temperature in the Fram Strait environment. J. Acous. Soc. Am., in press.

Semtner, A. J., Jr., 1987: A numerical study of sea ice and ocean circulation in the Arctic. J. Phys. Oceanogr. 17, 1077-1099.

Shang, E. C., Y. Y. Wang, and K. Naugolnykh, 1996: Numerical simulation on acoustic propagation in a complex environment-The Fram Strait. Proceedings, 3rd European Conf. on Underwater Acoustics, Heraclion, Crete, Greece, June 24-28, 165-170.

Simonsen, K. and P. M. Haugan, 1996: Heat budgets of the Arctic Mediterranean and sea surface heat flux parameterizations for the Nordic Seas. J. Geophys. Res. (Oceans) 101(C3), 6553-6576.

Voronovich, A. G., and E. C. Shang, 1995: A note on horizontal-refraction-modal tomography. J. Acous. Soc. Am. 98(5), pt. 1, 2708-2716.

Westervelt, P. J., 1963: Parametric acoustic array. J. Acous. Soc. Am. 35(4), 535-537.

Worcester, P. F., J. F. Lynch, W. M. L. Morawitz, R. Pawlowicz, P. J. Sutton, B. D. Cornuelle, O. M. Johannessen, W. H. Munk, W. B. Owens, R. Shuchman, and R. C. Spindel, 1993: Evolution of the large-scale temperature field in the Greenland Sea during 1988-1989 from tomographic measurements. Geophys. Res. Lett. 20, 2211-2214. 


\section{Appendix A: Fram Strait Workshop List of Attendees}

Dr. Er-Chang Shang

CIRES Research Associate

CIRES, University of Colorado/

NOAA, Environmental Technology

Laboratory, R/E/ET1

325 Broadway

Boulder, CO 80303-3328

eshang@etl.noaa.gov

Dr. James H. Churnside

Supervisory Physicist

NOAA/ERL/Environmental Technology

Laboratory, R/E/ET1

325 Broadway

Boulder, CO 80303-3328

jchurnside@etl.noaa.gov

Dr. Steven F. Clifford

Director

NOAA/ERL/Environmental Technology

Laboratory, R/E/ET

325 Broadway

Boulder, CO 80303-3328

sclifford@etl.noaa.gov

Dr. Bruce M. Howe

Senior Oceanographer

Applied Physics Laboratory

University of Washington

Seattle, WA 98105

howe@apl.washington.edu

Prof. Ola M. Johannessen

Director

Nansen Environmental and

Remote-Sensing Center

Bergen, Norway

admin@nrsc.no
Dr. James Lynch

Professor

Woods Hole Oceanographic Institution

Woods Hole, MA 02543

jim@vaquero.whoi.edu

Dr. Peter Mikhalevsky

Scientific Applications International

McLean, VA 22102

peter@oahu.osg.saic.com

Dr. Walter Munk

Professor

Scripps Institution of Oceanography

La Jolla, CA 92093-0225

wmunk@igpp.ucsd.edu

Prof. Konstantin Naugolnykh

CIRES Research Associate

CIRES, University of Colorado/

NOAA, Environmental Technology

Laboratory, R/E/ET1

Boulder, CO 80303-3328

knaugolnyk@etl.noaa.gov

Dr. Alexander Voronovich

CIRES Research Associate

CIRES, University of Colorado/

NOAA, Environmental Technology

Laboratory, R/E/ET1

Boulder, CO 80303-3328

avoronovich@etl.noaa.gov

Dr. Yun-Yu Wang

CIRES Research Associate

CIRES, University of Colorado/

NOAA, Environmental Technology

Laboratory, R/E/ET1

Boulder, CO 80303-3328

ywang@etl.noaa.gov 


\section{Appendix B: Fram Strait Workshop Agenda}

\section{FRAM STRAIT WORKSHOP}

September 25-26, 1996

NOAA/ERL/ETL

Boulder, Colorado USA

Wednesday, September 25, 1996

9:00 a.m. Welcome

9:15 a.m. Workshop Overview and Purpose

9:45 a.m. Fram Strait Monitoring as Part of a General Problem of Arctic Warming

Steven F. Clifford

Ola M. Johannessen

Peter N. Mikhalevsky

10:15 a.m. Discussion

10:30 a.m. Break

11:00 a.m. Notes on Monitoring to Large Picture of Flux into the Arctic

11:30 a.m. Acoustical Tomography Monitoring of Fram Strait

12:00 p.m. Preliminary Results of Numerical Simulation on Acoustic Propagation Across the Fram Strait

12:30 p.m. Lunch

2:00 p.m. Horizontal-Refraction Model Technique in the Acoustical Tomography of the Ocean

Alexander Voronovich

2:30 p.m. On the Numerical Simulation of the Ocean Temperature and Stream Velocity Acoustical Measurement in the Fram Strait Environment: Pilot Experiment Planning

3:00 p.m. Comments on the Fram Strait Tomography

3:30 p.m. Break

4:00 p.m. Numerical Simulation of Fram Strait Acoustical Monitoring: Discussion

5:30 p.m. Break

Thursday, September 26, 1996

9:00 a.m. Planning of Pilot Experiment and Feasibility Tests

10:30 a.m. Break

11:00 a.m. Ten-Year Scientific Plan on Fram Strait Monitoring: Discussion

12:30 p.m. Lunch

2:00 p.m. Ten-Year Scientific Plan on Fram Strait Monitoring: Discussion 4:30 p.m. Summary of Workshop

Konstantin Naugolnykh 



A000031608855 